\title{
Yönetim muhasebesi sistemi ve stratejik planlamanın firma performansına etkisi
}

\author{
The effect of management accounting system and strategic planning on \\ firm performance
}

\author{
Gökhan Özer ${ }^{1}$ \\ Canan Doğru²
}

1 Prof. Dr., Gebze Teknik Üniversitesi İşletme Fakültesi, Kocaeli, Türkiye, gokozerhan@gmail.com

ORCID: 0000-0002-3255-998X

2 Doktora Öğrencisi, Gebze Teknik Üniversitesi İşletme Fakültesi, Kocaeli, Türkiye, cdogru@gtu.edu.tr

ORCID: 0000-0002-0826-0830

Sorumlu Yazar/Corresponding Author: Gökhan Özer,

Gebze Teknik Üniversitesi İşletme Fakültesi, Kocaeli, Türkiye gokozerhan@gmail.com

Başvuru/Submitted: 30/04/2021

Revizyon/Revised: 30/05/2021

Kabul/Accepted: 3/06/2021

Yayın/Online Published: 25/06/2021

Atıf/Citation: Özer, G., \& Doğru, C., Yönetim muhasebesi sistemi ve stratejik planlamanin firma performansına etkisi, bmij (2021) 9 (2): 694-713, doi: https://doi.org/10.15295/bmij.v9i2.1828

\section{Öz}

Yönetim muhasebesi sisteminden sağlanan bilginin önemi, faydaları ve kullanımının durumsal faktörler altında performans üzerindeki etkisi daha önce yapılan çalışmalarda araştırılmıştır. Literatürde yönetim muhasebesi sisteminin firma performansı üzerindeki pozitif etkisini gösteren çalışmalar bulunmaktadır. Ancak bu ilişkiyi açıklayacak çalışmalara ihtiyaç duyulmaktadır. Bu çalışmada, yönetim muhasebesi sistemi bilgisi kullanımının önemli bir yönetsel faaliyet olan stratejik planlama üzerindeki etkisi ve stratejik planlamanın yönetim muhasebesi sistemi ve firma performansı arasındaki aracı etkisi incelenmiştir. İstanbul Sanayi Odası' nın açıkladığı Türkiye' nin en büyük 500 sanayi kuruluşu içerisinde yer alan 75 firmadan anket yoluyla elde edilen veriler PLS-SEM ile analiz edilmiştir. Araştırma sonucunda, yönetim muhasebesi sisteminin stratejik planlama üzerinde pozitif etkisi olduğu ve yönetim muhasebesi sisteminin firma performansı üzerindeki etkisinin kısmen stratejik planlama aracıllğıyla gerçekleştiği bulgusuna ulaşılmıştır. Bu bulgu, yönetim muhasebesi sistemi ve firma performansı arasındaki ilişkiyi kısmen açıklaması bakımından önem arz etmektedir. Sonuç olarak, firma kaynak ve ihtiyaçları gözetilerek, strateji ve hedeflere göre tasarlanmış yönetim muhasebesi sisteminin stratejik planlamanın başarısındaki rolü ile performansı arttırabileceği ortaya çıkmıştır.

Anahtar Kelimeler: Yönetim Muhasebesi Sistemi, Stratejik Planlama, Firma Performansı

Jel Kodları: M4, M1, L25

\begin{abstract}
In previous studies, the effect of the importance, usefulness, and use of information provided by the management accounting system on performance under contextual factors has often been investigated. Although there are findings in the literature indicating that management accounting positively impacts firm performance, which is a distant outcome, further research is needed to explain this relationship. In the present study, using management accounting system information on strategic planning, an important managerial activity, and the mediating effect of strategic planning between the management accounting system and firm performance were examined. PLS-SEM analyzed the data collected through surveys from 75 companies listed in Turkey's Largest 500 Industrial Firms. As a result of the research, it has been observed that the management accounting system has a positive effect on strategic planning and the effect of the management accounting system on firm performance is partially through strategic planning. This finding is crucial as it partially explains the relationship between the management accounting system and firm performance. Consequently, it has been revealed that the management accounting system designed according to the company's strategies and objectives while considering its resources and needs can improve performance by playing a role in the success of strategic planning.
\end{abstract}

Keywords: Management Accounting System, Strategic Planning, Firm Performance

Jel Codes: M4, M1, L25 


\section{Extended Abstract}

\section{The effect of management accounting system and strategic planning on firm performance}

\section{Literature}

\section{Research subject}

The business environment is becoming more complex due to many factors, such as increasing uncertainty and competition, technological changes, economic developments, and changes in consumer behaviour. Therefore, a successful management process requires sophisticated information systems to promptly provide adequate information (Bouwens and Abernethy, 2000). The management accounting system (MAS) is an integral part of the management process because it provides managers with planning, decision-making, and control activities through the systematic use of management accounting (Chenhall, 2003). Although there are findings in the literature that MAS improves firm performance (Mia and Winata, 2014; Nguyen, 2018), more empirical studies are needed to explain the relationship between MAS and firm performance.

Companies must be able to adapt to changing conditions in order to survive in today's complex business environment. Strategic planning, which is a part of strategic management, is a managerial tool widely used in companies for this purpose. The effect of strategic planning on firm performance has been extensively researched in previous studies. Even though different findings have been reached, the researchers' consensus is that strategic planning improves firm performance (Wolf and Floyd, 2017).

MAS information is required during the strategic planning process to monitor and analyse the environment, develop alternative strategies, and determine and control the strategy. Besides, researchers have argued that the effectiveness of MAS depends on its alignment with the firm's goals and strategy. As a result, it is considered that the integration of MAS and strategic planning is critical and that the support of the sophisticated MAS in the strategic planning process will improve the company's performance.

\section{Research purpose and importance}

The purpose of this study was to examine the effect of management accounting system and strategic planning on firm performance and the mediating effect of strategic planning on the relationship between the management accounting system and firm performance. This research is necessary because few studies explain the relationship between management accounting and firm performance.

\section{Contribution of the article to the literature}

According to the findings of this study, both management accounting system and strategic planning have a positive effect on firm performance, and strategic planning has a complementary mediation effect in the relationship between MAS and firm performance. Consequently, it has been revealed that the management accounting system designed according to the company's strategies and objectives while considering its resources and needs can improve performance by playing a role in the success of strategic planning.

\section{Design and method}

\section{Research type}

This research relied on quantitative methods.

\section{Research problems}

The present study was designed to investigate the role of MAS in strategic planning and the effect of MAS on firm performance through strategic planning, based on companies listed in Turkey's Largest 500 Industrial Firms published by the Istanbul Chamber of Industry.

\section{Data collection method}

Managers from the companies listed in Turkey's Largest 500 Industrial Firms were contacted for the study, and 79 firms participated. First, the data was collected through email surveys. Then, after the validity check, 75 questionnaires were analyzed.

\section{Quantitative/qualitative analysis}

Partial least squares structural equation modelling (PLS-SEM) was used to test the research model. PLS-SEM (SmartPLS v.3.3.3, Ringle et al., 2015) can work with complex models and small sample sizes (Hair et al., 2017). Therefore, it is also appropriate for analyzing the second-order constructs (management accounting system; firm performance) in our research model.

\section{Research model}

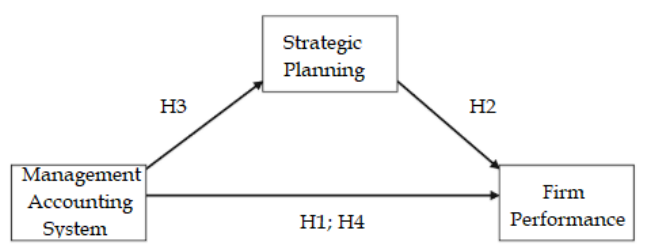

Figure 1: Research Model 


\section{Research hypotheses}

H1: Management accounting system has a positive effect on firm performance.

H2: Strategic planning has a positive effect on firm performance.

H3: Management accounting system has a positive effect on strategic planning.

H4: Management accounting system positively affects firm performance through strategic planning (mediating effect of strategic planning).

\section{Findings and discussion}

\section{Findings as a result of analysis}

As a result of the research, it has been observed that the management accounting system has a positive effect on strategic planning and the effect of the management accounting system on firm performance is partially through strategic planning.

\section{Hypothesis test results}

According to the research results, the management accounting system has a positive and significant effect on firm performance $(\beta=0.333 ; \mathrm{CI}=[0.086 ; 0.538] ; \mathrm{p}<0.01)$. H1 hypothesis was supported. Strategic planning has a positive and significant effect on firm performance $(\beta=0.382 ; \mathrm{CI}=[0.121 ; 0.613], \mathrm{p}<0.01)$. The $\mathrm{H} 2$ hypothesis was supported. Management accounting system has a positive and significant effect on strategic planning $(\beta=0.622 ; \mathrm{CI}=[0.420 ; 0.755], \mathrm{p}<0.001)$. H3 was supported. In addition to the management accounting system's direct positive and significant effect on firm performance (H1), management accounting system also has a positive and significant indirect effect on firm performance through strategic planning $(\beta=0.238(0.622 \times 0.382)$; $\mathrm{CI}=[0.074 ; 0.435], \mathrm{p}<0.05)$. Both the direct and indirect effects of the management accounting system on firm performance were significant and positive; complementary partial mediation was supposed. Thus, the H4 hypothesis was supported. Furthermore, when indirect effects are considered, the total effect of the management accounting system on firm performance is greater than the the effect of strategic planning (strategic planning $\beta=0.382<$ management accounting system $\beta=0.571(\beta=0.333+\beta=0.238)$.

\section{Discussing the findings with the literature}

This study found that the management accounting system had a positive effect on strategic planning. As a result, the management accounting system can be considered an essential determinant of strategic planning. Similarly, Frezatti et al., (2011) argued that the failure of strategic planning could result from an inadequate management accounting system. Therefore, in the success of strategic planning, managers need to design the management accounting system by its objectives and strategy, taking into account its resources and needs.

Other research findings are consistent with previous studies that found a positive relationship between the management accounting system and firm performance (Mia, 1993; Mia and Winata, 2014; Nguyen, 2018) and strategic planning and firm performance (Glaister et al., 2008). Moreover, it has been proven that the management accounting system increases firm performance through its role in strategic planning.

\section{Conclusion, recommendation, and limitations}

\section{Results of the article}

Both the management accounting system and strategic planning positively affect firm performance. However, the management accounting system has a more significant effect on firm performance than strategic planning. It has also revealed that strategic planning has a complementary mediation effect on the relationship between management accounting and firm performance. Sophisticated management accounting systems increase firm performance through their role in the success of the strategic planning process.

\section{Suggestions based on results}

Based on the research results, it is recommended that managers review the management accounting systems in their firms in terms of firm strategy and goals, then consider how they can enhance firm performance by improving its integration with strategic planning.

\section{Limitations of the article}

As with any empirical study, this study has limitations that open up future research opportunities. First, the sample size was limited to 75 large manufacturing firms. The research model can be tested with larger samples and data from small and mediumsized enterprises in future studies. Second, firm characteristics were not included in the analysis. The research model can be expanded by adding control variables such as firm age, firm size, industry. Future studies can also examine how contextual factors such as environmental uncertainty, competitive strategy, and organizational culture can affect the relationships in the research model. Some other mediating variables can be introduced to explain better the relationship between the management accounting system and firm performance in future studies. 


\section{Giriş}

Artan belirsizlik ve rekabet, teknolojik değişimler, ekonomik gelişmeler, tüketici davranışlarındaki değişim gibi pek çok faktör nedeniyle iş ortamı daha karmaşık bir hal almaktadır. Böyle bir ortamda, başarılı bir yönetim süreci, yeterli bilgiyi zamanında sağlayacak gelişmiş bilgi sistemlerini gerektirmektedir (Bouwens ve Abernethy, 2000). Sistematik bir biçimde kullanılan yönetim muhasebesi sistemi (YMS), yöneticilere planlama, karar alma ve kontrol faaliyetleri için sağladığı bilgiler ile yönetim sürecinin önemli bir parçasını oluşturmaktadır (Chenhall, 2003; Rasid, Isa ve Ismail, 2014). Literatürdeki çalışmaların çoğu, durumsal faktörlerin (çevresel belirsizlik, rekabet yoğunluğu, örgüt yapısı, rekabet stratejisi vb.) YMS tasarımındaki rolü ve YMS'nin özellikle yönetsel performansa etkisine odaklanmıştır. Görece daha az sayıda olan YMS ve firma performansı çalışmalarında, YMS'nin firma performansını pozitif yönde etkilediği görülmüştür. Ancak YMS ve firma performansı arasındaki ilişkiyi açıklayacak daha fazla ampirik çalışmaya ihtiyaç duyulmaktadır.

Bugünün karmaşık iş ortamında firmaların ayakta kalması, değişen koşullara ayak uydurabilmeyi gerektirmektedir. Stratejik yönetimin bir parçası olan stratejik planlama bu amaçla firmalarda yaygın olarak kullanılan yönetsel bir araçtır. Stratejik planlama, firmanın yönünü belirleyen, sistematik, rasyonel, periyodik ve adım adım izlenen bir süreç olarak tanımlanmaktadır (Armstrong, 1982). Stratejik planlamanın firma performansı üzerindeki etkisi, yapılan çalışmalarda sıklıkla araştırılmıştır.

Greenley (1994), stratejik planlamanın firma performansı üzerindeki etkisini araştıran 29 ampirik çalışma belirlemiş ve bunları üç grupta sınıflandırmıştır. İlk grupta (12 çalışma) stratejik planlamanın firma performansı üzerinde pozitif etkisi olduğu, ikinci grupta ( 9 çalışma) stratejik planlama ve firma performansı arasında anlamlı bir ilişki olmadığı ve üçüncü grupta (8 çalışma) stratejik planlamanın firma performansı üzerinde negatif etkisi olduğu bulgusuna ulaşılmıştır. Miller ve Cardinal (1994) 26 çalışmanın meta analizi sonucunda ve Shea-Van Fossen, Rothstein ve Korn (2006) 39 çalışmanın meta analizi sonucunda stratejik planlamanın firma performansı üzerinde pozitif etkisi olduğu sonucuna ulaşmıştır. Araştırmacılar, stratejik planlamanın firma performansı üzerindeki etkisinin pozitif yönde olduğu ve farklı bulguların metodolojik farklılıklardan kaynaklandığını düşünmektedirler (Miller ve Cardinal, 1994; Shea-Van Fossen vd., 2006; Wolf ve Floyd, 2017).

Stratejik planlama sürecinde, çevrenin izlenmesi ve analizi, alternatif stratejilerin oluşturulması, stratejinin belirlenmesi ve kontrolünde yönetim muhasebesi bilgisine ihtiyaç duyulmaktadır. Öte yandan, araştırmacılar YMS'nin etkinliğinin firmanın hedefleri ve stratejisiyle uyumlu olmasına bağlı olduğunu ileri sürmüşlerdir. Bu nedenle, YMS ve stratejik planlamanın entegrasyonun önemli olduğu, gelişmiş YMS sisteminin stratejik planlama sürecindeki desteği ile firma performansını artıracağı düşünülmektedir.

Bu bağlamda, çalışmamızda YMS'nin stratejik planlamadaki rolü ve YMS'nin stratejik planlama aracılığıyla firma performansı üzerinde etkisi olup olmadığı araştııılmaktadır.

Çalışma literatüre birkaç açıdan katkı sunmaktadır. (1) YMS sağladığı bilginin dört özelliğini kapsayacak şekilde ikinci seviye yapı olarak analiz edilmiştir. (2) YMS bilgisi kullanımının stratejik planlama üzerindeki pozitif etkisi gösterilmiştir. Gelişmiş YMS'nin stratejik planlamanın bir göstergesi olduğu ortaya konmuştur. (3) Stratejik planlamanın, YMS ve firma performansı arasındaki kısmi aracı rolü, diğer bir ifadeyle YMS'nin stratejik planlama aracılığıyla da firma performansını pozitif yönde etkilediği gözlemlenmiştir.

\section{Literatür incelemesi ve hipotez geliştirme}

Araştırmanın modeli, kaynak tabanlı teoriye dayanılarak oluşturulmuştur. Rekabet avantajı yaratmada firmanın benzersiz kaynaklarının kullanımı ve geliştirilmesine dayanan kaynak tabanlı yaklaşımdan (Barney, 1991) hareketle, yönetim muhasebesi sistemi ve stratejik planlamanın firma performansına etkisine odaklanılmıştır.

\section{Yönetim muhasebesi sistemi (YMS) ve firma performansı}

Chenhall ve Morris (1986), yönetim muhasebesi sistemini, sistemden sağlanan bilginin dört özelliği üzerinden tanımlamıştır. Sağlanan bilginin kapsamı (dar-geniş), zamanındalığı (yavaş/standarthızlı/talebe göre özelleştirilmiş), detay düzeyi (özet-çok detaylı) ve bütünleşme düzeyi (tek bölüm -tüm bölümler), sistemin gelişmişliğini göstermektedir (Soobaroyen ve Poorundersing, 2008).

Sadece finansal nitelikli geçmiş verilere ve kurum içi olaylara odaklanan YMS, öngörülebilir durumlarda ve rutin işler için alınacak kararlarda kullanılabilecek dar kapsamlı bilgi sağlar. Oysaki gelecek odaklı, kurum içi ve kurum dışı koşulları göz önünde bulunduran, finansal ve finansal olmayan geniş kapsamlı bilgi sağlayan bir YMS, yöneticilere değişen çevreyi algılamada, strateji geliştirmede, 
mevcut stratejinin değerlendirilmesinde, alternatif kararların maliyetlerini karşılaştırmada, rutin olmayan yönetsel kararlarda, performansı değerlendirmede ve iyileştirme için gerekleri belirlemede katkı sağlayacaktır. Zamanındalık, gerektiğinde bilgiye ulaşılabilirliği ve raporlama sıklığını ifade etmektedir. Kurumda meydana gelen değişimler ve olaylar sonrası raporlamanın hızlıca yapılması, harekete geçmede önemlidir. Raporlama sıklı̆̆ı da ayrıca bir geri bildirim faaliyeti olarak görülebilir. Detay düzeyi, belirli alanlara (sorumluk merkezleri, fonksiyonel alanlar gibi) veya dönemlere göre bilginin özetlenmesini ifade etmektedir. Yöneticilerin tüm kurumu kapsayan büyük miktarda bilgiyi hızlı ve karşılaştırılabilir bir şekilde elde etmesi, kararlarının hem kendi hem de diğer bölümlerdeki etkilerini görmesini, diğer alternatifleri göz önünde bulundurmasını ve hem bölüm içindeki hem de bölümler arasındaki girdi ve çıktı arasındaki ilişkiyi daha iyi anlamasını sağlayacaktır. Böylece sorunların çözümünde de bütüncül bir bakış açısı geliştirilebilecektir. Bütünleşme düzeyi, alt birimlerin etkileşimlerini ifade eder. Birimlerin kararlarında ve hedeflerindeki farklılıkların görülmesini sağlar. Nihai amacı firma performansını iyileştirmek olan yönetici için, birimlerin bu ortak amaca hizmet etmesi ve aralarındaki uyumun sağlanmasında bütünleşik bilginin önemi büyüktür. Bütünleşik bilgi ayrıca belirsizliği azaltabilir, öğrenmeyi arttırabilir ve yeni fikirlere ışık tutabilir (Chenhall ve Morris, 1986; Bouwens ve Abernethy, 2000).

Literatürde YMS bilgisinin dört boyutunun birlikte değerlendirildiği çalışmalar sınırlıdır (Lal ve Hassel, 1998; Agbejule, 2005; Hammad, Jusoh ve Ghozali, 2013; Ismail, Isa ve Mia, 2018; Nguyen, 2018; Ghasemi, Habibi, Ghasemlo ve Karami, 2019). Çoğu çalışmada, sistemi genel olarak yansıttığı düşünüldüğgunden ve ölçüm kolaylığı nedeniyle YMS bilgisinin sadece "kapsam" boyutunun ele alındığı görülmektedir (Mia, 1993; Abernethy ve Guthrie, 1994; Mia ve Chenhall, 1994; Chong ve Chong, 1997; Mia ve Clarke, 1999; Mia, 2000; Linn, Casey, Johnson ve Ellis, 2001; Chong ve Eggleton, 2003; Sharma, Jones ve Ratnatunga, 2006; Agbejule ve Burrowes, 2007; Naranjo-Gil ve Hartman, 2007; Cheng, 2012; Mia ve Winata, 2014; Nguyen, Mia, Winata ve Chong, 2017). Ayrıca, YMS bilgisinin iki ya da üç boyutunun dahil edildiği çalışmalar da bulunmaktadır (Gul ve Chia, 1994; Fisher, 1996; Tsui, 2001; Chiou, 2011; Novas, Alves ve Sousa, 2017). Tüm boyutların incelenmediği çalışmalarda, sistemin bütününe ilişkin değerlendirmelerin yetersiz kaldığı düşünülmektedir (Soobaroyen ve Poorundersing, 2008).

Sağlanan bilginin değerlendirilmesinde de araştırmacılar tarafından farklı yaklaşımlar sergilenmiştir. Bazı çalışmalarda "bilginin faydasının ve öneminin" (Bouwens ve Abernethy, 2000; Naranjo-Gil ve Hartman, 2007; Chiou, 2011; Cheng, 2012; Novas vd., 2017); diğer çalışmalarda ise "bilginin ulaşılabilirliği/mevcut olması ve kullanımının" (Mia ve Chenhall, 1994; Tsui, 2001; Chong ve Eggleton, 2003; Agbejule, 2005; Sharma vd., 2006; Agbejule ve Burrowes, 2007; Hammad vd., 2013; Mia ve Winata, 2014; Ismail vd., 2018; Nguyen, 2018; Ghasemi vd., 2019) değerlendirilmesi istenmiş̧tir. Bilginin faydalı olmasının ya da öneminin değerlendirilmesi, kullanııların varsayımsal çıkarımlarına dayanabileceğinden mevcut durumu yansitamayabileceği düşünülmektedir (Soobaroyen ve Poorundersing, 2008). Çalışmalardaki bu farklılıklar, bulguların karşılaştırılmasını zorlaştırmaktadır.

Örgüt yapılarının etkinliğinin teknoloji ve çevre gibi durumsal faktörlere göre değiştiği, yönetim tekniklerinin örgütün bağlamı ve yapısına bağlı olduğu görüşüne dayanan durumsallık teorisi (Lawrence ve Lorsch, 1967), yönetim muhasebesi alanında "tüm koşullarda tüm organizasyonlara uygulanabilecek tek uygun muhasebe sistemi olamayacağı" görüşünü getirmiştir (Otley, 1980). Bu bağlamda yönetim muhasebesi sistemi tasarımının örgütler arasında neden farklılık gösterdiğini açıklamaya yönelik olarak, dışsal/çevresel, içsel/örgütsel ve bireysel/psikolojik faktörlerin etkisi araştırılmıştır. Çevresel belirsizlik (Agbejule, 2005; Chiou, 2011; Hammad vd., 2013) ve pazar rekabeti (Mia ve Clarke, 1999; Patiar ve Mia, 2008; Mia ve Winata, 2014) araştırılan ana çevresel değişkenlerdir. Örgüt yapısı (Gul ve Chia, 1994; Chia, 1995; Hammad vd., 2013), kültür (Tsui, 2001; Etemadi, Dilami, Bazaz ve Parameswaran, 2009), strateji (Chong ve Chong, 1997; Bouwens ve Abernethy, 2000; Ghasemi, Mohamad, Karami, Hafiz Bajuri ve Asgharizade, 2015), pazar yönelimi (Nguyen, 2018), üretim uygulamaları (Mia, 2000; Mia ve Winata, 2008; Ismail vd., 2018) ve teknoloji (Ghasemi vd., 2019) yönetim muhasebesi sistemi üzerine etkisi araştırılan içsel/örgütsel değişkenlerdir. Liderlik tarzı (Nguyen vd., 2017), belirsizlik toleransı (Lal ve Hassel, 1998; Chiou, 2011), kontrol odağ1 (Fisher, 1996; Chong ve Eggleton, 2003) ve görev belirsizliği (Chong, 1996; Soobaroyen ve Poorundersing, 2008) araştırılan bireysel/psikolojik değişkenlerdir. Bazı çalışmalarda anılan değişkenlerin YMS (bağımlı değişken) üzerindeki etkisi araştırılırken, diğer çalışmalarda YMS'nin aracılığıyla performans (çoğunlukla yönetsel) üzerindeki etkisi incelenmiştir.

YMS ve performans alanındaki çalışmalar incelendiğinde, YMS'nin sıklıkla yönetsel performansa etkisinin araştırıldığı görülmektedir. Önceki çalışmalar, YMS'den sağlanan bilginin yöneticilerin yönetsel performansı üzerinde pozitif etkisi olduğunu göstermiştir (Agbejule, 2005; Soobaroyen ve Poorundersing, 2008; Etemadi vd., 2009; Cheng, 2012; Hammad vd., 2013; Nguyen vd., 2017; Ghasemi, 
Mohamad, Karami, Bajuri ve Asgharizade, 2016; Ghasemi vd., 2019). YMS'nin iş birim performansı ve firma performansı üzerindeki etkisinin araştırıldığı çalışmalar nispeten daha azdır. YMS ve iş birim performansı arasındaki ilişkiye bakıldığında, YMS bilgisi kullanımı arttıkça bölüm performansının arttığı gözlemlenmiştir (Abernethy ve Guthrie, 1994; Chong ve Chong, 1997; Mia ve Clarke, 1999; Patiar ve Mia, 2008; Ismail vd., 2018). Genel firma performansı açısından değerlendirildiğinde, YMS'nin yöneticilerin planlama, kontrol ve karar alma faaliyetlerindeki pozitif etkisi, kurumların genel performansına da pozitif yönde etki edecektir (Mia, 1993). Mia (2000), tam zamanında üretimi (JIT) benimseyen kuruluşların, yönetim muhasebesi sisteminden daha fazla bilgi aldıklarında karlarının daha yüksek olduğunu; Mia ve Winata (2014), rekabetin yoğun olduğu ortamlarda JIT uygulamalarının YMS bilgileri ile desteklenmesinin daha yüksek finansal performansa neden olduğu sonucuna ulaşmıştır. Ghasemi vd. (2015), rekabetteki değişimin, YMS ve stratejideki değişimle doğrudan ve dolaylı olarak performansta artış sağladığı bulgusuna ulaşmıştır. Novas vd., (2017), YMS'nin insan sermayesinin ve yapısal sermayenin gelişiminde pozitif etkisi olduğunu ve yapısal sermayenin, kurumsal performansla pozitif ve anlamlı bir bağlantısı olduğunu göstermiş̧tir. Ismail vd. (2018), YMS bilgisi kullanımının, entegre üretim uygulamalarının benimsenmesi ve firma performansı arasında aracı etkisi olduğunu ortaya koymuştur. Nguyen (2018), YMS kullanımının (tüm bilgi boyutlarında) pazar yönelimi ve firma performansı arasında aracı etkisi olduğunu; muhasebecilerin stratejik karar almaya katılım derecesinin, pazar yönelimi ve YMS kullanımı arasındaki pozitif ilişkiyi arttırdığını belirtmiştir. Hutahayan (2020), inovasyon stratejinin YMS aracılığıyla firma performansı üzerinde pozitif etkisi olduğu bulgusuna ulaşmıştır. Pedrosso, Gomes ve Yasin (2020), YMS'nin yönetsel performansı ve yönetsel performans aracılığıyla da firma performansını arttırdığını belirtmiştir. Bu değerlendirmeler ışı̆̆ında;

$\mathrm{H}_{1}$ : Yönetim muhasebesi sisteminin, firma performansı üzerinde pozitif yönlü bir etkisi vardır.

\section{Stratejik planlama ve firma performansı}

Stratejik planlama, organizasyonlarda yaygın olarak kullanılan etkili yönetim araçlarından biridir (Meissner, 2014; Wolf ve Floyd, 2017). Literatürde pek çok farklı tanımlama olmakla birlikte genel vurgu, stratejik planlamanın strateji geliştirme, uygulama ve kontrolünü sağlayan sistematik ve periyodik bir süreç olduğudur (Wolf ve Floyd, 2017). Strateji geliştirme süreci, kurum misyon ve uzun vadeli hedeflerinin belirlenmesi, iç ve dış çevrenin analizi, alternatif stratejilerin üretilmesi ve değerlendirilmesini kapsar. İzleyen adımlar, oluşturulan stratejinin uygulanması ve periyodik olarak belirlenen kriterler kullanılarak kontrolüdür (Hopkins ve Hopkins, 1997).

Stratejik planlama uygulaması firmaya birçok açıdan fayda sağlar. Kurum içinde ortak bir amacın yaratılmasını, üst yönetim ve tüm çalışanlar tarafından benimsenmesini, kurum içi iletişimi ve iş birliğini geliştirir (McCarthy ve Minichiello, 1996). Kurum içi iletişim ve katılımın gelişmesi karar alma sürecini de pozitif yönde etkileyecektir (Grant, 2003). Firma kaynaklarının belirlenen önceliklerle optimize edilmesiyle operasyonel verimlilik artacak, dinamik ve karmaşık çevre koşullarında örgütsel esneklik ve adaptasyon yeteneği gelişecektir (Arend, Zhao, Song ve Im, 2017). Araştırmacılar stratejik planlamanın, anılan faydalarıyla sonuç olarak firma performansını pozitif yönde etkileyeceğini belirtmektedirler.

Stratejik planlamanın özellikle finansal firma performansına etkisi, alanda en çok çalışılan konu olmuştur (Wolf ve Floyd, 2017). Literatürdeki ilk değerlendirmelerde (Armstrong, 1982; Pearce, Freeman ve Robinson 1987; Miller ve Cardinal, 1994; Greenley, 1994), stratejik planlamanın firmadaki faydasını ve finansal performansa pozitif etkisini işaret eden çokça çalışma olmakla birlikte anlamlı bir etkinin olmadığı ve hatta negatif etkiyi bildiren çalışmaların varlığı, araştırmacıları bulgulardaki tutarsızlı̆̆ın kaynağını anlamaya yöneltmiştir (Wolf ve Floyd, 2017). Bulgulardaki farklılığın kaynağı olarak, ciddi metodolojik farklılıklara ve zayıflıklara dikkat çekilmiştir. Özetle, ana metodolojik farklılıklara/eksikliklere, stratejik planlamaya ilişkin ortak bir tanımın olmaması, endüstriyel farklılıkların göz ardı edilmesi ve performans ölçütünün seçimi örnek verilebilir (Falshaw, Glaister ve Tatoglu, 2006). Sonraki çalışmalarda da yine farklı bulgular görülmektedir. Örneğin, Falshaw vd. (2006) İngiltere'de yerleşik firmalarla yürüttüğü çalışmasında formal planlama süreci ile subjektif firma performansı arasında anlamlı bir ilişki bulamamıştır. Öte yandan, Glaister, Dincer, Tatoglu, Demirbag ve Zaim (2008) Türkiye'deki firmalarla yürüttüğü çalışmasında formal stratejik planlama ve firma performansı arasındaki pozitif ilişkiyi; çevresel türbülans, örgüt yapısı ve firma büyüklüğünün bu ilişkideki düzenleyici etkisini göstermiştir. Benzer şekilde, Dibrell, Craig ve Neubaum (2014), formal stratejik planlama sürecinin planlama esnekliğini pozitif etkilediğini ve her ikisinin yenilikçiliğin tam aracılığıla firma performansı üzerindeki pozitif dolaylı etkisini gözlemlemiştir. Bu değerlendirmeler 1şı̆̆ında;

$\mathbf{H}_{2}$ : Stratejik planlamanın firma performansı üzerinde pozitif yönlü bir etkisi vardır. 


\section{Yönetim muhasebesi sistemi (YMS) ve stratejik planlama}

Firma etkinliğinde önemli bir araç olan stratejik planlama sürecinde gerçekleşen durum analizi, amaç ve hedeflerin belirlenmesi, planların yapılması, faaliyetlerin izlenmesi ve değerlendirilmesi aşamaları, yönetim muhasebesi sisteminden sağlanan bilgiyi gerektirmektedir (Frezatti, Aguiar, Guerreiro ve Gouvea, 2011). Bu nedenle, stratejik planlamanın başarısı, bilgi sisteminin planlama sürecinde ihtiyaç duyulan bilgiyi karşılamasına bağlıdır. Firma kaynakları ve öncelikleri göz önünde bulundurularak, firma strateji ve hedefleriyle uyumlu olacak şekilde tasarlanmış gelişmiş bir yönetim muhasebesi sistemi, zamanında sağladığı nitelikli bilgi ile stratejik planlama sürecinin etkinliğini arttıracaktır. Buna karşın, YMS'nin yetersiz olması durumunda, bilginin zamanında aktarılamaması ya da dar kapsamlı olması, stratejik planlamanın etkinliğini azaltacaktır. Literatürde YMS'nin stratejik planlamadaki önemine ilişkin görüşler bulunmakla birlikte, bu ilişki üzerine ampirik çalışmalar kısıtlıdır. Örneğin, Frezatti vd. (2011) yönetim muhasebesi sistemi tarafından üretilen bilginin niteliklerinin, stratejik ve bütçe planlama süreçlerini nasıl etkilediğini incelediği çalışmasında, zayıf planlama sürecinin yetersiz yönetim muhasebesi sisteminden kaynaklandığını ortaya koymuştur. Bu bağlamda çalışmamızda YMS'nin stratejik planlamadaki rolünün belirlenmesi amaçlanmaktadır.

$H_{3}$ : Yönetim muhasebesi sisteminin stratejik planlama üzerinde pozitif yönlü bir etkisi vardır.

\section{Yönetim muhasebesi sistemi (YMS), stratejik planlama ve firma performansı}

Önceki çalışmalar incelendiğinde, yönetim muhasebesi sisteminin firma performansı (Mia ve Winata, 2014; Nguyen, 2018) ve stratejik planlamanın firma performansı (Glaister vd., 2008) üzerindeki pozitif etkisi görülmüş̧ür. Yönetim muhasebesi sisteminin stratejik planlamadaki rolü göz önünde bulundurulduğunda, performansı arttırdığı gözlemlenen bu iki yönetsel aracın entegre olduğu firmalarda performansın daha yüksek seviyede olacağı düşünülmektedir. Gelişmiş bir yönetim muhasebesi sistemi, zamanında sağladığı nitelikli bilgi ile, başarılı bir stratejik planlama sonucunda firma performansını arttıracaktır. Bu düşünceden hareketle çalışmamızda, yönetim muhasebesi sisteminin firma performansına etkisinde stratejik planlamanın aracı rolünün belirlenmesi amaçlanmaktadır.

$\boldsymbol{H}_{4}$ : Yönetim muhasebesi sisteminin stratejik planlama aracılığıla firma performansı üzerinde pozitif yönlü dolaylı bir etkisi vardır (stratejik planlamanin aracı etkisi).

Araştırmanın modeli Şekil 1'de sunulmuştur.

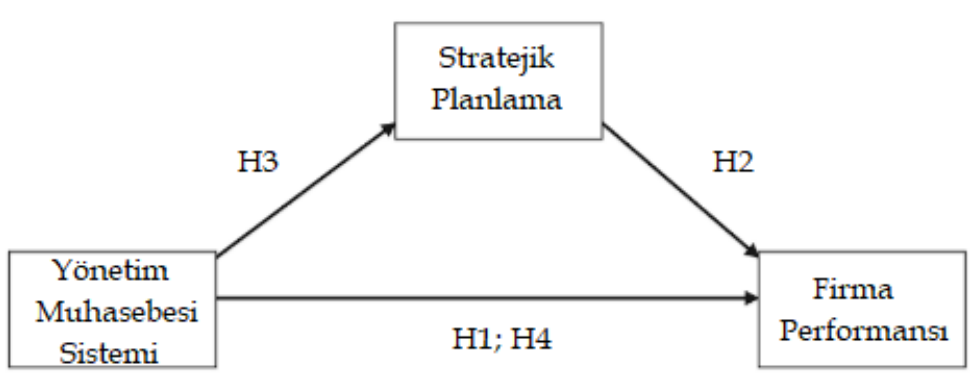

Şekil 1: Araştırmanın Modeli

\section{Metodoloji}

\section{Veri toplama süreci ve örneklem}

Araştırmanın evrenini, İstanbul Sanayi Odası' nın 2019 yılı Türkiye' nin en büyük 500 sanayi kuruluşu listesinde ismi açıklanan 465 özel firma oluşturmaktadır. Araştırma kapsamında veriler, İnsan Araştırmaları Etik Kurulu' nun 18.02.2021 tarih 2021/07-02 sayılı etik onay kararına dayanılarak ŞubatNisan 2021 döneminde toplanmıştır. Firmalardaki genel müdür ve üst düzey yöneticilere Linkedin ve telefon aracılığıyla ulaşılmaya çalışılmış ve süreç sonucunda 79 firmadan geri dönüş sağlanmıştır. Anket formlarının değerlendirilmesi sonucunda özensiz doldurulduğu anlaşılan 4 adet anket çıkartılmış ve kalan 75 adet anket ile analiz yapılmıştır. Çalışma konusu, firmada ancak üst düzey yöneticilerin sahip olabileceği bilgiyi gerektirmektedir. Geri dönüş oranı düşüklügüü (\%17), üst düzey yöneticilere ulaşma zorluğu ve kendilerinin zaman kıstı nedeniyle anlaşılabilirdir. Örneklemin yeterliliğini belirlemek için istatistiksel güç analizi yapılmış ve $G^{*}$ Power 3.1.9.7 yazılımından 
faydalanılmıştır. Modelde bir endojen değişkeni açıklayan maksimum değişken sayısı ikidir. Orta derecede etki büyüklüğü (0.15), \%80 güç (sosyal bilimlerde kabul edilen minimum değer) ve 0.05 anlamlılık düzeyinde gerekli örneklem büyüklüğü 68 olarak hesaplanmıştır. 75 firmadan oluşan örneklemimizin gücü, açıklanan varyans (R2: 0.415) ve 0.05 anlamlılık düzeyinde test edildiğinde, \%99'dur. Dolayısıyla bu çalışma için örneklem büyüklüğü uygundur.

Katılımcıların demografik özellikleri ve görev aldıkları firmalara ilişkin bilgiler Tablo 1'de yer almaktadır. Özetle, katılımcı firmaların \%45'inin çalışan sayısı 250-999 aralığında olup, firmaların \%41'i 40 yıl ve daha uzun süredir faaliyetini sürdürmektedir. Katılımcıların büyük çoğunluğu (\%91) erkek olup, \%60'1 36-50 yaş aralığındadır. Katılımcıların \%7'si genel müdür, \%57'si mali işler yöneticisi ve \%36'sı diğer üst düzey yöneticilerden oluşmaktadır.

Tablo 1: Katılımcıların Demografik Özellikleri ve Firmaya İlişkin Bilgiler

\begin{tabular}{|c|c|c|c|c|}
\hline & Özellik & Grup & Frekans & Yüzde (\%) \\
\hline \multirow{16}{*}{$\begin{array}{l}\text { Katılımciların } \\
\text { Demografik } \\
\text { Özellikleri }\end{array}$} & \multirow[t]{2}{*}{ Cinsiyeti } & Kadın & 7 & 9 \\
\hline & & Erkek & 68 & 91 \\
\hline & \multirow[t]{3}{*}{ Yaş1 } & 35 ve alt 1 & 23 & 31 \\
\hline & & $36-50$ & 45 & 60 \\
\hline & & 50 ve üstü & 7 & 9 \\
\hline & \multirow[t]{2}{*}{ Eğitim Durumu } & Lisans & 50 & 67 \\
\hline & & Lisansüstü & 25 & 33 \\
\hline & Toplam Çalışma & 10 ve alt1 & 17 & 23 \\
\hline & \multirow[t]{2}{*}{ Süresi (y1l) } & $11-20$ & 34 & 45 \\
\hline & & 21 ve üstü & 24 & 32 \\
\hline & Bu Firmadaki Çalışma & 10 ve alt1 & 50 & 67 \\
\hline & \multirow{2}{*}{ Süresi (yil) } & $11-20$ & 16 & 21 \\
\hline & & 21 ve üstü & 9 & 12 \\
\hline & \multirow[t]{3}{*}{ Çalışılan Pozisyon } & Genel Müdür & 5 & 7 \\
\hline & & Mali İşler Yöneticisi & 43 & 57 \\
\hline & & Diğer Üst Düzey Yöneticiler & 27 & 36 \\
\hline \multirow{10}{*}{$\begin{array}{l}\text { Firmaya } \\
\text { İlişkin } \\
\text { Bilgiler }\end{array}$} & \multirow[t]{3}{*}{ Çalışan Sayısı } & $0-249$ & 14 & 19 \\
\hline & & $250-999$ & 34 & 45 \\
\hline & & 1000 ve üzeri & 27 & 36 \\
\hline & \multirow[t]{3}{*}{ Firma Yaşı (yıl) } & 20 ve alt1 & 16 & 21 \\
\hline & & $21-40$ & 28 & 37 \\
\hline & & 40 ve üstü & 31 & 41 \\
\hline & Firmanın Teknoloji & Yüksek & 3 & 4 \\
\hline & \multirow[t]{3}{*}{ Sinif1 (OECD) } & Orta Yüksek & 18 & 24 \\
\hline & & Orta Düşük & 28 & 37 \\
\hline & & Düşük & 26 & 35 \\
\hline
\end{tabular}

\section{Araştırmada kullanılan ölçekler}

Yönetim muhasebesi sisteminin gelişmişliğinin ölçümünde, Chenhall ve Morris (1986) tarafından geliştirilen ve bu alanda çalışan diğer araştırmacılar (Bouwens ve Abernethy, 2000; Agbejule, 2005; Soobaroyen ve Poorundersing, 2008; Nguyen vd., 2017) tarafından yaygın olarak kullanılan, sistemden sağlanan bilginin dört özelliğini (kapsam, zamanındalık, detay düzeyi, bütünleşme düzeyi) değerlendiren 20 maddeden oluşan dört boyutlu ölçek kullanılmıştır. Katılımcılardan, özellikleri belirtilen bilginin firmalarındaki sistemden ne ölçüde sağlandığını "(1) hiç mevcut değil-(5) her zaman mevcut" olacak şekilde sıralanmış 5'li Likert ölçeğinde değerlendirmeleri istenmiştir.

Stratejik planlamanın ölçümünde, Boyd ve Reuning-Elliott (1998) tarafından geliştirilen ve Sax ve Andersen (2019) tarafından kullanılan 5 maddeli ölçekten faydalanılmıştır. Katılımcıların firmalarında son üç yılda "(1) şirket misyonunun oluşturulması, (2) uzun vadeli planların hazırlanması (3-5 yıllık), (3) yıllık hedeflerin (satış hedefleri, verimlilik, pazar payları vb.) yapılması, (4) kısa vadeli planlama (kampanyalar, iş projeleri vb.) yapılması ve (5) şirketin stratejik hedeflerinin ve yerine getirilme derecesinin değerlendirilmesi" faaliyetlerine ne derece önem verildiğini "(1) çok az derecede-(5) çok yüksek derecede" olarak sıralanmış 5'li Likert ölçeğinde değerlendirmeleri istenmiştir.

Firma performansının ölçümünde, Govindarajan (1984), Mia ve Clarke (1999) ve Calantone, Cavusgil ve Zhao (2002) çalışmalarından faydalanılmıştır. Performans, finansal performans ve finansal olmayan performans olarak iki boyutta sübjektif olarak ölçülmüştür. Finansal olmayan performansın ölçümünde, katılımcılardan firmaların son üç yılda planlanan "(1) verimlilik, (2) maliyet, (3) kalite, (4) teslimat, (5) servis ve (6) personel gelişimi ile ilgili hedeflere ulaşma konusundaki performansını; finansal performansın ölçümünde "(1) toplam aktifler, (2) satış hacmi, (3) pazar payı, (4) karlılık, (5) satı̧ getirisi ve (7) aktif getiri ile ilgili hedeflere ulaşma" konusundaki performansını, "(1-2) ortalama altı, (3) orta, (4-5) ortalama üstü" olarak sıralanmış 5'Li Likert ölçeğinde değerlendirmeleri istenmiştir. 


\section{Analiz ve sonuçlar}

Araştırma hipotezlerinin test edilmesinde kısmi en küçük kareler yapısal eşitlik modellemesi (PLSSEM) kullanılmıştır. PLS-SEM, karmaşık modellerde, normal dağılım göstermeyen veri ve küçük örneklem büyüklüklerinde çalışabilmektedir (Hair, Hult, Ringle ve Sarstedt, 2017). Ayrıca araştırma modelimizde bulunan ikinci seviye yapının analizi için de uygundur.

PLS-SEM analizinde SmartPLS (v.3.3.3) yazılımından faydalanılmıştır (Ringle, Wende ve Becker, 2015). PLS-SEM analizi, ölçüm modelinin değerlendirilmesi ve yapısal modelin değerlendirilmesi olmak üzere iki aşamadan oluşmaktadır.

\section{Ölçüm modeli değerlendirmesi}

Araştırma modelinde yer alan stratejik planlama birinci seviye yansıtıcı (reflective) yapıdadır. Yönetim muhasebesi sistemi, dört adet birinci seviye yansıtıcı yapıdan (kapsam, zamanındalık, detay düzeyi, bütünleşme düzeyi) oluşturulan yansıtıcı-yansıtıcı ikinci seviye yapıdadır. Benzer biçimde firma performansı, finansal ve finansal olmayan performans olarak birinci seviye yansitıcı yapilardan oluşturulan yansıtıcı-yansıtıcı ikinci seviye yapıdadır. Yüksek seviye ölçüm modelinin analizinde tekrarlayan gözlenen değişkenler yaklaşımı (repeated indicators approach) uygulanmıştır. $\mathrm{Bu}$ yaklaşımda ikinci seviye yapıyı oluşturacak birinci seviyelerdeki tüm göstergeler aynı zamanda ikinci seviye yapıya bağlanır (Hair vd., 2017).

Yüksek seviye ölçüm modelinin yer aldığı araştırma modeli değerlendirilirken ilk adım, tüm birinci seviye ölçüm modellerinin değerlendirilmesi; ikinci adım, yüksek seviye ölçüm modelinin, kendisinin ve kendine bağlı olmayan birinci seviye yapılar ile değerlendirilmesidir (Sarstedt, Hair, Cheah, Becker ve Ringle, 2019).

\section{Birinci seviye ölçüm modeli değerlendirmesi}

Araştırma modelindeki tüm birinci seviye yapılar yansıtıcı nitelikte olduğundan, ölçüm modeli içsel tutarlılık, yakınsak geçerlilik ve ayrışma geçerliliği açısından değerlendirilmiştir (Hair vd., 2017). Tablo 2'de birinci seviye ölçüm modeli analiz sonuçları sunulmuştur.

Tablo 2'de görüleceği üzere tüm birinci seviye yapıların Cronbach Alfa, rho_A ve CR (bileşik güvenilirlik) değerleri, eşik değeri olan 0,70'in üzerinde olduğundan içsel tutarlılık sağlanmıştır. 
Tablo 2: Birinci Seviye Ölçüm Modeli Analiz Sonuçları

\begin{tabular}{|c|c|c|c|c|c|c|}
\hline \multirow{2}{*}{$\begin{array}{l}\text { Birinci Seviye } \\
\text { Yap1 }\end{array}$} & \multirow[b]{2}{*}{ Madde } & \multicolumn{2}{|c|}{ Yakınsak Geçerlilik } & \multicolumn{2}{|c|}{ İçsel Tutarlılık } & \multirow[b]{2}{*}{ CR } \\
\hline & & Gösterge Yükü & AVE & Cronbach alfa & rho_A & \\
\hline \multirow[t]{5}{*}{ Kapsam } & KAP1 & 0.762 & 0.614 & 0.836 & 0.843 & 0.887 \\
\hline & KAP2 & 0.821 & & & & \\
\hline & KAP3 & 0.829 & & & & \\
\hline & KAP4 & 0.880 & & & & \\
\hline & KAP6 & 0.595 & & & & \\
\hline \multirow[t]{6}{*}{ Detay Düzeyi } & TOP2 & 0.771 & 0.657 & 0.895 & 0.898 & 0.920 \\
\hline & TOP3 & 0.788 & & & & \\
\hline & TOP4 & 0.815 & & & & \\
\hline & TOP5 & 0.796 & & & & \\
\hline & TOP6 & 0.888 & & & & \\
\hline & TOP7 & 0.802 & & & & \\
\hline \multirow[t]{3}{*}{ Bütünleşme düzeyi } & BUT1 & 0.869 & 0.793 & 0.869 & 0.869 & 0.920 \\
\hline & BUT2 & 0.880 & & & & \\
\hline & BUT3 & 0.921 & & & & \\
\hline \multirow[t]{3}{*}{ Zamanındalık } & ZAM2 & 0.898 & 0.719 & 0.803 & 0.815 & 0.884 \\
\hline & ZAM3 & 0.861 & & & & \\
\hline & ZAM4 & 0.780 & & & & \\
\hline \multirow[t]{5}{*}{ Stratejik Planlama } & STRPLN1 & 0.718 & 0.696 & 0.890 & 0.905 & 0.919 \\
\hline & STRPLN2 & 0.887 & & & & \\
\hline & STRPLN3 & 0.864 & & & & \\
\hline & STRPLN4 & 0.825 & & & & \\
\hline & STRPLN5 & 0.865 & & & & \\
\hline \multirow[t]{6}{*}{$\begin{array}{l}\text { Finansal Olmayan } \\
\text { Performans }\end{array}$} & NONFIN1 & 0.861 & 0.581 & 0.855 & 0.872 & 0.892 \\
\hline & NONFIN2 & 0.805 & & & & \\
\hline & NONFIN3 & 0.808 & & & & \\
\hline & NONFIN4 & 0.678 & & & & \\
\hline & NONFIN5 & 0.707 & & & & \\
\hline & NONFIN6 & 0.697 & & & & \\
\hline \multirow{7}{*}{$\begin{array}{l}\text { Finansal } \\
\text { Performans }\end{array}$} & FIN1 & 0.826 & 0.737 & 0.940 & 0.942 & 0.951 \\
\hline & FIN2 & 0.791 & & & & \\
\hline & FIN3 & 0.879 & & & & \\
\hline & FIN4 & 0.886 & & & & \\
\hline & FIN5 & 0.828 & & & & \\
\hline & FIN6 & 0.883 & & & & \\
\hline & FIN7 & 0.910 & & & & \\
\hline
\end{tabular}

Tüm maddeler için $\mathrm{p}<0,001$

Yakınsak geçerlilik, gösterge güvenilirliği (indicator reliability) ve ortalama açılanan varyans (AVE) değeri açısından değerlendirilmiştir. Gösterge güvenilirliği için gösterge yükünün 0.70 ve üzerinde olması istenmektedir. Ayrıca gösterge yükleri anlamlı olmalıdır. 0,40-0,70 arası değer alan göstergelerin ise ancak bileşik güvenilirlik ve AVE eşik değerinin sağlanması amacıyla çıkartılabileceği belirtilmiştir (Hair vd., 2017). Tablo 2'de görüleceği üzere tüm gösterge yükleri 0,50'nin üzerinde ve anlamlıdır $(p<0,001)$. Ayrıca tüm yapıların AVE değerleri eşik değeri olan 0,50 'nin üzerindedir. Dolayısıyla yakınsak geçerlilik sağlanmıştır.

Ayrışma geçerliliğinin test edilmesinde, son dönemde araştırmacılar, çapraz gösterge yükleri ve Fornell ve Larcker (1981) kriterinin yeterli olmadığını öne sürmekte ve Henseler, Ringle ve Sarstedt (2015) tarafından geliştirilen HTMT yaklaşımının kullanılmasını önermektedir (Sarstedt vd., 2019; Benitez, Henseler, Castillo ve Schuberth. 2020). Yine de ayrışma geçerliliği üç açıdan incelenmiştir. 
HTMT (Henseler vd., 2015), bir yapıyı oluşturan göstergelerin diğer yapıdaki göstergelerle olan korelasyonunun ortalamasının (heterotrait-heteromethod correlations), iki yapının kendisini oluşturan göstergelerinin ortalama korelasyonlarının (monotrait-heteromethod correlations) geometrik ortalamasına oranıdır. İki yapı arasında ayrışma geçerliliğinden söz edilebilmesi için HTMT değerinin kavramsal olarak birbirine yakın yapilar arasında 0,900; uzak yapilar arasında ise 0,850'nin altında olması gerekmektedir (Henseler vd., 2015). İlk incelemede, yönetim muhasebesi sistemi alt boyutlarından zamanındalık ve detay düzeyi arasındaki HTMT değerinin eşik değer üzerinde olduğu görülmüştür. Bu nedenle, gösterge çapraz yükleri incelenerek, iki yapıda yakın değerler alan TOP1 ve ZAM1 maddeleri ölçeklerden çıkarılmıştır. Çıkartılan maddeler sonrasında, Tablo 3'de görüleceği üzere YMS alt boyutları arasında HTMT $(<900)$ kriteri; diğer tüm HTMT değerlerinde $(<0,850)$ eşik değeri sağlanmıştır. Ayrıca, 5000 alt örneklemle çalıştırılan yeniden örnekleme metodu (bootstrapping) sonucunda confidence interval bias corrected değerleri, Tablo 3'de görüleceği üzere " 1 " değerini içermemektedir (Hair vd., 2017).

Tablo 3: HTMT Kriteri (Birinci Seviye Yapilar)

\begin{tabular}{lllllll}
\hline & $(1)$ & $(2)$ & $(3)$ & $(4)$ & $(5)$ & $(6)$ \\
\hline$(2)$ & 0.780 & & & & \\
& $(0.638 ; 0.881)$ & & & & \\
\hline$(3)$ & 0.568 & 0.650 & & & & \\
& $(0.326 ; 0.762)$ & $(0.482 ; 0.794)$ & & & & \\
\hline$(4)$ & 0.474 & 0.674 & 0.551 & & & \\
& $(0.240 ; 0.673)$ & $(0.477 ; 0.833)$ & $(0.303 ; 0.745)$ & & 0.727 & \\
\hline$(5)$ & 0.414 & 0.570 & 0.487 & & & \\
& $(0.217 ; 0.618)$ & $(0.362 ; 0.747)$ & $(0.241 ; 0.707)$ & $(0.554 ; 0.871)$ & & \\
\hline$(6)$ & 0.446 & 0.650 & 0.655 & 0.893 & 0.673 & \\
& $(0.252 ; 0.634)$ & $(0.435 ; 0.819)$ & $(0.440 ; 0.808)$ & $(0.796 ; 0.961)$ & $(0.506 ; 0.813)$ & \\
\hline$(7)$ & 0.451 & 0.610 & 0.711 & 0.759 & 0.560 & 0.898 \\
& $(0.212 ; 0.656)$ & $(0.422 ; 0.767)$ & $(0.487 ; 0.880)$ & $(0.597 ; 0.876)$ & $(0.345 ; 0.748)$ & $(0.759 ; 0.987)$ \\
\hline
\end{tabular}

(1) Finansal performans; (2) Finansal olmayan performans; (3) Stratejik Planlama; (4) Bütünleşme düzeyi; (5) Kapsam;

(6) Detay düzeyi; (7) Zamanındalık

Parantez içindeki değerler, 5000 alt örneklemle çalıştırılan yeniden örnekleme metodu (bootstrapping) sonucunda elde edilen confidence interval bias corrected değerleridir.

Ayrışma geçerliliğinin test edilmesinde başvurulan diğer yaklaşım, modeldeki her bir yapının karekökü alınmış AVE değerinin, yapının diğer tüm yapılarla olan korelasyon değerinden daha büyük olması gerektiğini ifade eden Fornell ve Larcker (1981) kriteridir. Tablo 4'de görüleceği üzere tüm yapılar için bu kriter sağlanmıştır.

Tablo 4: Fornell ve Larcker Kriteri

\begin{tabular}{|c|c|c|c|c|c|c|c|c|c|c|}
\hline & & $(1)$ & $(2)$ & (3) & $(4)$ & (5) & (6) & $(7)$ & $(8)$ & (9) \\
\hline (1) & Firma Performansı & $0.857^{*}$ & & & & & & & & \\
\hline (2) & $\begin{array}{l}\text { Finansal } \\
\text { Performans }\end{array}$ & $0.952^{* *}$ & 0.858 & & & & & & & \\
\hline (3) & $\begin{array}{l}\text { Finansal Olmayan } \\
\text { Performans }\end{array}$ & $0.899^{* *}$ & 0.723 & 0.762 & & & & & & \\
\hline (4) & Stratejik Planlama & 0.589 & 0.528 & 0.576 & 0.834 & & & & & \\
\hline (5) & $\begin{array}{l}\text { Yönetim } \\
\text { Muhasebesi Sistemi }\end{array}$ & 0.570 & 0.463 & 0.628 & 0.622 & $0.734^{*}$ & & & & \\
\hline (6) & Bütünleşme düzeyi & 0.531 & 0.428 & 0.588 & 0.497 & $0.887^{* *}$ & 0.890 & & & \\
\hline (7) & Kapsam & 0.443 & 0.365 & 0.480 & 0.424 & $0.768^{* *}$ & 0.619 & 0.783 & & \\
\hline (8) & Detay Düzeyi & 0.513 & 0.410 & 0.574 & 0.595 & $0.941^{* *}$ & 0.791 & 0.588 & 0.811 & \\
\hline (9) & Zamanındalık & 0.474 & 0.393 & 0.508 & 0.616 & $0.820^{* *}$ & 0.643 & 0.458 & 0.760 & 0.848 \\
\hline
\end{tabular}

$\left({ }^{*}\right)$ İkinci seviye yapılar için AVE değeri, SmartPLS yazılımında doğrudan hesaplanamamakta, manuel hesaplamayı gerektirmektedir (Sarstedt vd., 2019). Tabloda manuel hesaplama sonucu sunulmuştur. İkinci seviye yapının AVE değerinin manuel olarak hesaplanması ve kendine bağlı olmayan diğer yapılarla ayrışma geçerliliği izleyen bölümde yer almaktadır.

$\left.{ }^{* *}\right)$ İkinci seviye yapı ve kendisini oluşturan birinci seviye yapı arasında ayrışma geçerliliği aranmamaktadır (Hair vd., 2017)

Ayrışma geçerliliğ̈inin test edilmesinde ayrıca çapraz yükler tablosu incelenmiştir. KAP5 maddesinin diğer yapıdaki çapraz yükü, bağlı olduğu yapıdaki gösterge yükünden daha yüksek değer aldığından ölçekten çıkartılmıştır. Madde çıkartıldıktan sonra kalan tüm göstergelerin bağlı olduğu yapıdaki yükünün, diğer yapılardaki tüm çapraz yüklerinden daha büyük olduğu tespit edilmiştir.

Bu sonuçlar tüm birinci seviye yapılar arasında ayrışma geçerliliğinin sağlandığını göstermektedir. 


\section{İkinci seviye ölçüm modeli değerlendirmesi}

Ölçüm modelinin değerlendirilmesinde ikinci adım, yüksek seviye ölçüm modelinin, kendisinin ve kendine bağlı olmayan birinci seviye yapılar ile değerlendirilmesidir (Sarstedt vd., 2019). Yönetim muhasebesi sistemi ve firma performansı yüksek seviye yapıları yansıtıcı-yansıtıcı nitelikte olduğundan içsel tutarlılık, yakınsak geçerlilik ve ayrışma geçerliliği açısından değerlendirilmiştir (Sarstedt vd., 2019).

Yüksek seviye yapılarda, içsel tutarlılığın test edilmesinde başvurulan Cronbach alfa ve CR değerleri ile ayrışma geçerliliğinin değerlendirilmesinde başvurulan Henseler vd. (2015) HTMT kriteri SmartPLS yazılımında doğrudan hesaplanamadığından, söz konusu değerler Sarstedt vd. (2019) tarafından uygulanan yöntem izlenerek manuel olarak hesaplanmıştır.

İkinci seviye ölçüm modeli değerlendirme sonuçları Tablo 5'de sunulmuştur.

Tablo 5: İkinci Seviye Ölçüm Modeli Değerlendirmesi

\begin{tabular}{|c|c|c|c|c|c|}
\hline \multirow[b]{2}{*}{$\begin{array}{c}\text { İkinci Seviye } \\
\text { Yapı }\end{array}$} & \multirow[b]{2}{*}{$\begin{array}{c}\text { Birinci Seviye } \\
\text { Yapı }\end{array}$} & \multicolumn{2}{|c|}{ Yakınsak Geçerlilik } & \multicolumn{2}{|c|}{ İçsel Tutarlılık } \\
\hline & & $\begin{array}{l}\text { Korelasyon } \\
\text { Yüküu }\end{array}$ & AVE & Cronbach alfa & CR \\
\hline \multirow{4}{*}{$\begin{array}{l}\text { Yönetim } \\
\text { Muhasebesi } \\
\text { Sistemi }\end{array}$} & Kapsam & $0.768^{*}$ & \multirow[t]{4}{*}{0.734} & \multirow[t]{4}{*}{0,878} & \multirow[t]{4}{*}{0.916} \\
\hline & Detay Düzeyi & $0.941^{*}$ & & & \\
\hline & Bütünleşme düzeyi & $0.887^{*}$ & & & \\
\hline & Zamanındalık & $0.820^{*}$ & & & \\
\hline \multirow{3}{*}{$\begin{array}{l}\text { Firma } \\
\text { Performans1 }\end{array}$} & Finansal Olmayan & $0.899^{*}$ & \multirow[t]{3}{*}{0.857} & \multirow[t]{3}{*}{0,839} & \multirow[t]{3}{*}{0.923} \\
\hline & Performans & & & & \\
\hline & Finansal Performans & $0.952^{*}$ & & & \\
\hline
\end{tabular}

İkinci seviye yapıda artık kendini oluşturan birinci seviye yapılar gösterge niteliğindedir (Sarstedt vd., 2019). Tablo 5'de görüleceği üzere ikinci seviye yapının göstergeleri olan birinci seviye yapıların korelasyon yükü 0,70 değerinin üzerinde ve anlamlı olduğundan ikinci seviye yapılar için gösterge güvenilirliği sağlanmıştır. Yüksek seviye yapının AVE değeri, birinci seviye yapıların, bağlı olduğu ikinci seviye yapı ile arasındaki korelasyon yükü karelerinin ortalamasıdır. Yönetim muhasebesi sitemi için AVE değeri $\left(0.768^{2}+0.941^{2}+0.887^{2}+0.820^{2}\right) / 4=\mathbf{0 . 7 3 4}$; firma performansı için AVE değeri $\left(0.899^{2}\right.$ $\left.+0.952^{2}\right) / 2=\mathbf{0 . 8 5 7}$, eşik değer $(0,50)$ üzerinde olduğundan her iki yüksek seviye yapı için yakınsak geçerlilik sağlanmıştır.

İçsel tutarlılığın test edilmesinde, Cronbach alfa değeri aşağıdaki şekilde hesaplanmıştır.

$$
\text { Cronbach } \alpha=\frac{\mathrm{M} \cdot \mathrm{r}^{-}}{\left(1+(\mathrm{M}-1) \cdot \mathrm{r}^{-}\right)}
$$

$\mathrm{r}^{-}$birinci seviye yapılar arasındaki ortalama korelasyonu ifade etmektedir. M, yüksek seviye yapıyı oluşturan birinci seviye yapı sayısıdır. Yönetim muhasebesi sistemi, dört adet birinci seviye yapıdan (kapsam, detay düzeyi, bütünleşme düzeyi, zamanındalık) oluştuğundan $M=4$ 'dür ve yönetim muhasebesi sistemini oluşturan birinci seviye yapıların korelasyon ortalaması 0.643 'dür. Yönetim muhasebesi sistemi için Cronbach alfa değeri $(4 \times 0.643) /[1+(3 \times 0.643)]=0.878$ olarak hesaplanmıştır. Firma performansı, finansal ve finansal olmayan performans olmak üzere iki adet birinci seviye yapıdan oluştuğundan $\mathrm{M}=2^{\prime}$ dir ve birinci seviye iki yapı arasındaki korelasyon, 0.723 'dür. Firma performansı için Cronbach alfa değeri $(2 \times 0.723) /[1+(1 \times 0.723)]=0.839$ olarak hesaplanmıştır.

İçsel tutarlılığın değerlendirilmesinde başvurulan diğer yöntem bileşik güvenilirlik (CR), aşağıdaki şekilde hesaplanmıştır.

$$
C R=\frac{\left(\sum_{i=1}^{M} l_{i}\right)^{2}}{\left(\sum_{i=1}^{M} l_{i}\right)^{2}+\sum_{i=1}^{M} \operatorname{var}\left(e_{i}\right)}
$$

$e_{i}$ birinci seviye yapının $(i)$ ölçüm hatasını; $\operatorname{var}\left(e_{i}\right), 1-l_{i}^{2}$ olarak tanımlanan ölçüm hatasının varyansını ifade etmektedir.

Yönetim muhasebesi sistemi için CR değeri, aşağıdaki şekilde 0.916 olarak hesaplanmıştır.

$$
C R=\frac{(0.768+0.941+0.887+0.820)^{2}}{(0.768+0.941+0.887+0.820)^{2}+\left[\left(1-0.768^{2}\right)+\left(1-0.941^{2}\right)+\left(1-0.887^{2}\right)+\left(1-0.820^{2}\right)\right.}=0.916
$$


Firma performansı için CR değeri, aşağıdaki şekilde 0.923 olarak hesaplanmıştır.

$$
C R=\frac{(0.899+0.952)^{2}}{(0.899+0.952)^{2}+\left[\left(1-0.899^{2}\right)+\left(1-0.952^{2}\right)\right.}=0.923
$$

Yukarıda gösterildiği üzere yapılan hesaplamalar sonucunda hem yönetim muhasebesi sistemi hem de firma performansı için Cronbach alfa ve CR değerlerinin 0,70 eşik değeri üzerinde olduğu görülmüştür. Dolayısıyla, araştırma modelindeki yüksek seviye yapılar için içsel tutarlılık sağlanmıştır.

Yüksek seviye yapıların ayrışma geçerliliğinin değerlendirilmesi için HTMT kriterinin hesaplanmasında, yüksek seviye yapı heterotrait-heteromethod korelasyonları, modeldeki diğer yapının göstergelerinin ikinci seviye yapıyı oluşturan birinci seviye yapılardaki çapraz yükleridir. Yüksek seviye yapı monotrait-heteromethod korelasyonları, ikinci seviye yapıyı oluşturan birinci seviye yapıların korelasyonlarıdır.

Tablo 6: Çapraz Yükler Tablosu

\begin{tabular}{|c|c|c|c|c|c|c|c|}
\hline \multirow[b]{2}{*}{ Yap1 } & \multirow[b]{2}{*}{ Gösterge } & \multicolumn{2}{|c|}{$\begin{array}{l}\text { Firma Performans1 } \\
\text { (ikinci seviye yapı) }\end{array}$} & \multicolumn{4}{|c|}{$\begin{array}{c}\text { Yönetim Muhasebesi Sistemi } \\
\text { (ikinci seviye yapı) }\end{array}$} \\
\hline & & $\begin{array}{l}\text { Finansal } \\
\text { Performans }\end{array}$ & $\begin{array}{l}\text { Finansal } \\
\text { Olmayan } \\
\text { Performans }\end{array}$ & $\begin{array}{l}\text { Bütünleşme } \\
\text { düzeyi }\end{array}$ & Kapsam & $\begin{array}{l}\text { Detay } \\
\text { Düzeyi }\end{array}$ & Zamanındalık \\
\hline \multirow{5}{*}{$\begin{array}{l}\text { Stratejik } \\
\text { Planlama }\end{array}$} & STRPLN1 & 0.381 & 0.525 & 0.305 & 0.265 & 0.313 & 0.310 \\
\hline & STRPLN2 & 0.469 & 0.492 & 0.398 & 0.317 & 0.539 & 0.491 \\
\hline & STRPLN3 & 0.409 & 0.403 & 0.422 & 0.378 & 0.585 & 0.598 \\
\hline & STRPLN4 & 0.365 & 0.413 & 0.335 & 0.389 & 0.428 & 0.481 \\
\hline & STRPLN5 & 0.546 & 0.565 & 0.561 & 0.403 & 0.567 & 0.635 \\
\hline
\end{tabular}

Örneğin yüksek seviye yapı firma performansı ve stratejik planlama için HTMT değeri hesaplanırken, heterotrait-heteromethod korelasyonlar, stratejik yapı göstergelerinin ikinci seviye yapıyı oluşturan finansal performans ve finansal olmayan performans birinci seviye yapılarındaki çapraz yükleridir. Yüksek seviye yapılar (firma performansı ve yönetim muhasebesi sistemi) ve modeldeki diğer birinci seviye yapı (stratejik planlama) için çapraz yükler Tablo 6 ' da sunulmuştur. Stratejik planlama ve firma performans1 heterotrait-heteromethod korelasyonlar1 ortalamasi $(0.381+0.469+0.409+0.365+$ $0.546+0.525+0.492+0.403+0.413+0.565) / 10=0.456$ ' dır. Monotrait-heteromethod korelasyonları için, stratejik planlamada gösterge korelasyonlarını ortalaması (0.617) alınmış, ikinci seviye yapı firma performansında ise birinci seviye yapiları olan finansal performans ve finansal olmayan performans arasındaki korelasyona (0.723) bakılmıştır. Sonuç olarak, firma performansı ve stratejik planlama için HTMT kriteri (heterotrait-heteromethod korelasyonları ortalamasının, monotrait-heteromethod korelasyonlarının geometrik ortalamasına oranı) 0.683 olarak hesaplanmıştır.

$$
\text { HTMT (Firma Performansı, Stratejik Planlama) }=0.456 / \sqrt{0.617 \times 0.723}=0.683
$$

Yüksek seviye yapılara ilişkin hesaplanan diğer HTMT değerleri Tablo 7'de sunulmuştur. Tüm HTMT değerleri 0.850 eşik değeri altında olduğundan yüksek seviye yapılarda ayrışma geçerliliği sağlanmıştır (Henseler vd., 2015).

Tablo 7: İkinci Seviye Ölçüm Modeli için HTMT Kriteri

\begin{tabular}{|c|c|c|c|c|}
\hline \multirow{2}{*}{ HTMT $(1,2)$} & $\begin{array}{c}\text { Heterotrait- } \\
\text { heteromethod } \\
\text { korelasyonlar1 } \\
\text { ortalamas1 }\end{array}$ & $\begin{array}{c}\text { (1) Monotrait- } \\
\text { heteromethod } \\
\text { korelasyonlar1 } \\
\text { ortalamas1 }\end{array}$ & $\begin{array}{c}\text { (2) Monotrait- } \\
\text { heteromethod } \\
\text { korelasyonlar1 } \\
\text { ortalamas1 }\end{array}$ & HTMT \\
\cline { 2 - 5 } & $(a)$ & $(b)$ & 0.617 & $(a / \sqrt{b x c})$ \\
\hline (FP, STRPLN) & 0.456 & 0.723 & 0.617 & 0.683 \\
\hline (YMS, STRPLN) & 0.436 & 0.643 & 0.723 & 0.692 \\
\hline (YMS, PER) & $0.468^{*}$ & 0.643 & 0.686 \\
\hline
\end{tabular}

FP: Firma Performansı; STRPLN: Stratejik Planlama; YMS: Yönetim Muhasebesi Sistemi

$\left.{ }^{*}\right)$ İkinci seviye yapıyı oluşturan birinci seviye yapıların, diğer ikinci seviye yapıyı oluşturan birinci seviye yapılarla olan korelasyonunun ortalamasi.

Hem birinci seviye ölçüm modelinin hem de yüksek seviye ölçüm modelinin değerlendirilmesi sonucunda modelin geçerliliği ve güvenilirliği ispatlanmıştır. 


\section{Yapısal model değerlendirmesi}

Yapısal modelde doğrusallık, yol katsayıları, R2 ve f2 (etki büyüklüğ̈̈) değerleri PLS algoritması ile; yol katsayılarının anlamlılığı 5000 alt örneklemle çalıştırılan yeniden örnekleme metodu (bootstrapping) ile test edilmiştir. Yapısal modelin analizi Şekil 2'de ve analiz sonuçları Tablo 8'de sunulmuştur.

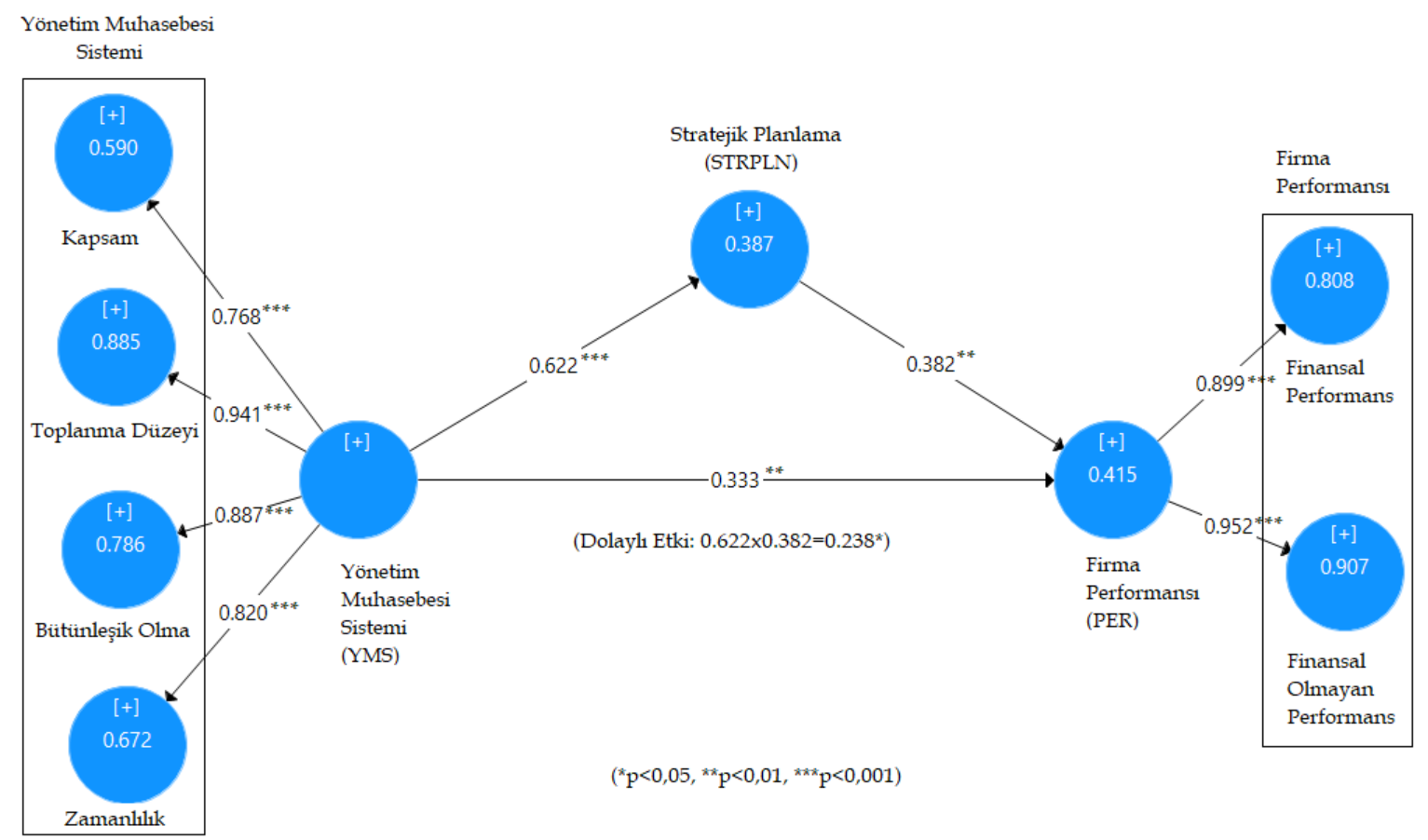

Şekil 2: Yapısal Model Analizi

Tablo 8: Yapısal Model Analiz Sonuçları

\begin{tabular}{lllll}
\hline Doğrudan Etki & $\boldsymbol{\beta}$ katsayısı & $\mathbf{9 5 \%}$ Bca CI & (f2) etki büyüklüğü & VIF \\
\hline YMS-STRPLN & $0.622^{* * *}$ & $(0.420 ; 0.755)$ & 0.632 & 1.000 \\
YMS-PER & $0.333^{* *}$ & $(0.086 ; 0.538)$ & 0.116 & 1.632 \\
STRPLN-PER & $0.382^{* *}$ & $(0.121 ; 0.613)$ & 0.153 & 1.632 \\
Dolaylı Etki & & & \\
YMS-PER & $0.238^{*}$ & $(0.074 ; 0.435)$ & & \\
& $\mathbf{R 2}$ & $\mathbf{Q 2}$ & \\
STRPLN & 0.387 & 0.243 & & \\
PER & 0.415 & 0.229 & \\
$\left(^{*}\right)$ p $<0.05,(* *) p<0.01,\left({ }^{* * *}\right)$ p $<0.001$ & & & \\
$($ YMS: Yönetim Muhasebesi Sistemi; STRPLN: Stratejik Planlama; PER: Firma performansi)
\end{tabular}

Parantez içindeki değerler, 5000 alt örneklemle çalıştırılan yeniden örnekleme metodu (bootstrapping) sonucunda elde edilen confidence interval bias corrected değerleridir.

Yapısal Modelde VIF (Variance Inflation Factor) değerleri, eşik değeri 3'ün altında olduğundan doğrusallık sorunu olmadığı söylenebilir (Hair, Risher, Sarstedt ve Ringle, 2019).

Analiz sonucuna göre, yönetim muhasebesi sisteminin firma performansı üzerinde pozitif ve anlamlı bir etkisi vardır $(\beta=0.333 ; C I=[0.086 ; 0.538] ; p<0.01)$. Bu bulgu yönetim muhasebesi sistemi değişkeninde meydana gelen artış ve azalışların, firmanın performansına aynı şekilde yansıdığını ortaya koymaktadır. Bu nedenle H1 hipotezinin desteklendiğini söylemek mümkündür.

Stratejik planlamanın firma performansı üzerinde pozitif ve anlamlı bir etkisi vardır $(\beta=0.382$; $\mathrm{CI}=[0.121 ; 0.613], \mathrm{p}<0.01)$. Bu bulgu stratejik planlama değişkeninde meydana gelen artış ve azalışların, firmanın performansına aynı şekilde yansıdığını ortaya koymaktadır. Bu bulguya göre H2 hipotezi desteklenmiştir. Yukarıdaki iki bulgu dikkate alındığında, hangi değişkenin firma performansı üzerinde daha güçlü doğrudan bir etkisi olduğu sorgulanabilir. Firma performansını aynı anda 
açıklayan iki değişkenin $\beta$ değerleri, stratejik planlamanın firma performansını yönetim muhasebesi sistemine oranla daha yüksek düzeyde doğrudan açıklama gücüne sahip olduğunu ortaya koymaktadır.

Yönetim muhasebesi sisteminin stratejik planlama üzerinde pozitif ve anlamlı bir etkisi vardır $(\beta=0.622$; $\mathrm{CI}=[0.420 ; 0.755], \mathrm{p}<0.001)$. Yani, yönetim muhasebesi sistemindeki artış ya da azalışlar stratejik planlama üzerinde de aynı yönlü bir etki doğurmaktadır ve bu etki önemlidir. Bu bulguya göre, H3 hipotezi desteklenmiştir.

Yönetim muhasebesi sisteminin firma performansına doğrudan pozitif ve anlamlı etkisinin (H1) yanı sıra, stratejik planlama aracılığıyla dolaylı etkisi de pozitif ve anlamlıdır $(\beta=0.238(0.622 \times 0.382)$; $\mathrm{CI}=[0.074 ; 0.435], \mathrm{p}<0.05)$. Yönetim muhasebesi sisteminin firma performansı üzerindeki doğrudan ve dolaylı etkisi aynı yönlü (pozitif) ve anlamlı olduğundan stratejik planlamanın, yönetim muhasebesi sistemi ve firma performansı arasındaki ilişkide kısmi aracilık etkisi (complementary mediation) bulunmaktadır (Hair vd., 2017). Bu bulguya göre, H4 hipotezi desteklenmiştir. Ayrıca direkt etkilerde firma performansının üzerinde stratejik planlamanın daha yüksek etkiye sahip olduğu ortaya çıkmıştı. Dolaylı etkiler dikkate alındığında ise yönetim muhasebesi sisteminin firma performansı üzerindeki toplam etkisi (stratejik planlama $\beta=0.382<$ yönetim muhasebesi sistemi $\beta=(\beta=0.333+\beta=0.238)=0.571$ ) $0.571^{\prime}$ dir. Bu toplam etkiler bakımından firma performansı üzerinde en yüksek etkiye sahip değişkenin yönetim muhasebesi sistemi olduğunu ortaya koymaktadır.

Belirli bir bağımsız değişkenin bağımlı değişken üzerindeki etkisinin ne derece önemli olduğunu gösteren (f2) etki büyüklüğü değerlendirme sonuçları Tablo 8'de sunulmuştur. Cohen (1988), etki büyüklügüunü (f2) düşük (0.02), orta (0.15) ve yüksek (0.35) olarak tanımlamıştır. Sarstedt vd. (2017) f2 değerinin 0.02 altında bir değer alması durumunda ise etkiden söz edilemeyeceğini bildirmiştir. Model etki büyüklüğü açısından değerlendirildiğinde, yönetim muhasebesi sisteminin stratejik planlama üzerinde yüksek etkisi (0.632) olduğu; stratejik planlamanın performans üzerinde orta derecede etkisi (0.153) olduğu görülmüştür. Yönetim muhasebesi sisteminin firma performansı üzerindeki düşük etkisinin (0.116), stratejik planlamanın aracılık etkisinden kaynaklandığı söylenebilir.

Örneklem içi uyum (in-sample fit) testi için R2 değerleri hesaplanmıştır. Stratejik planlamanın \%38 ve firma performansının \%41 oranında açıklandığı tespit edilmiştir. Endojen değişkenlerin tahmin gücünü test etmek için Blindfolding analizi yapılmıştır. Değişkenlerin tahmin gücü katsayısının (Q2) sıfırdan büyük olması, tahmin gücüne sahip olduğunu göstermektedir (Bkz. Tablo 8). Ancak araştırmacılar son dönemde, modelin örneklem dişı tahmin gücünün (out of sample predictive power) test edilmesinde daha ileri bir yöntem olan PLSpredict prosedürünün izlenmesini tavsiye etmektedir (Sarstedt vd., 2019). $\mathrm{Bu}$ nedenle, modele PLSpredict prosedürü ( 3 folds 10 repetetions) uygulanmıştır (Shmueli, Ray, Velasquez Estrada ve Chatla, 2016; Shmueli, Sarstedt, Hair, Cheah, Ting, Vaithilingam ve Ringle, 2019). Tüm göstergelerin PLS-SEM Q2 tahmin değerleri sıfırın üzerinde bulunmuştur. Dolayısıyla model tahminsel uygunluğa sahiptir (Shmueli vd., 2019). Firma performansı hedef yapı olduğundan, firma performansı göstergelerinin RMSE ve MAE değerlerine odaklanılmıştır (Bkz. Tablo 9). Tüm göstergeler için hem RMSE hem de MAE değerlerinin PLS-SEM'de Lineer modele (LM) göre daha düşük değer aldığı tespit edilmiştir. Dolayısıyla modelin yüksek tahmin gücü olduğu söylenebilir (Shmueli vd., 2019).

Tablo 9: PLSpredict Analiz Sonucu

\begin{tabular}{lccccccc}
\hline & \multicolumn{3}{c}{ PLS-SEM } & \multicolumn{2}{c}{ LM } & \multicolumn{2}{c}{ PLS-SEM - LM } \\
\cline { 2 - 8 } & RMSE & MAE & $\mathbf{Q}^{2}$ _predict & RMSE & MAE & RMSE & MAE \\
\hline FIN1 & 0,722 & 0,535 & 0,153 & 0,937 & 0,717 & $-0,215$ & $-0,182$ \\
FIN2 & 0,955 & 0,755 & 0,071 & 1,311 & 1,006 & $-0,356$ & $-0,251$ \\
FIN3 & 0,913 & 0,726 & 0,115 & 1,196 & 0,953 & $-0,283$ & $-0,227$ \\
FIN4 & 0,993 & 0,814 & 0,117 & 1,359 & 1,073 & $-0,366$ & $-0,259$ \\
FIN5 & 0,767 & 0,600 & 0,189 & 0,995 & 0,758 & $-0,228$ & $-0,158$ \\
FIN6 & 0,861 & 0,676 & 0,063 & 1,125 & 0,891 & $-0,264$ & $-0,215$ \\
FIN7 & 0,811 & 0,642 & 0,173 & 1,139 & 0,894 & $-0,328$ & $-0,252$ \\
NONFIN1 & 0,742 & 0,595 & 0,286 & 0,894 & 0,746 & $-0,152$ & $-0,151$ \\
NONFIN2 & 0,875 & 0,705 & 0,248 & 1,133 & 0,896 & $-0,258$ & $-0,191$ \\
NONFIN3 & 0,613 & 0,490 & 0,193 & 0,769 & 0,623 & $-0,156$ & $-0,133$ \\
NONFIN4 & 0,555 & 0,430 & 0,181 & 0,719 & 0,576 & $-0,164$ & $-0,146$ \\
NONFIN5 & 0,582 & 0,450 & 0,187 & 0,725 & 0,553 & $-0,143$ & $-0,103$ \\
NONFIN6 & 0,823 & 0,652 & 0,126 & 0,901 & 0,735 & $-0,078$ & $-0,083$ \\
\hline (FIN· Finansal Performans; NONFIN: Finansal Olmayan Performans) & & & &
\end{tabular}

(FIN: Finansal Performans; NONFIN: Finansal Olmayan Performans) 


\section{Sonuç ve öneriler}

Çalışmada, yönetim muhasebesi sistemi, stratejik planlama ve firma performansı ilişkilerinin incelenmesi amaçlanmıştır.

Yönetim muhasebesi sistemi ve stratejik planlama ilişkisi literatürde işaret edilmekle birlikte, konuya ilişkin ampirik çalışma azlığı, bizi bu ilişkinin incelenmesine yöneltmiştir. Çalışmamızda, yönetim muhasebesi sisteminin stratejik planlamayı pozitif yönde etkilediği bulgusuna ulaşılmıştır. Dolayısıyla, yönetim muhasebesi sisteminin stratejik planlamanın önemli bir belirleyicisi olduğu görülmüştür. Benzer şekilde, Frezatti vd. (2011) stratejik planlamanın başarısızlığının yetersiz yönetim muhasebesi sisteminden kaynaklanabileceğini bildirmiştir. Dolayısıyla, stratejik planlamanın başarısında, yöneticilerin, yönetim muhasebesi sistemini, kaynaklarını ve ihtiyaçlarını gözeterek, firma hedeflerine ve stratejisine uygun olacak şekilde tasarlamaları önem arz etmektedir.

Literatürde "yönetim muhasebesi sistemi ve firma performansı" ve "stratejik planlama ve firma performansı" ilişkisini inceleyen ayrı ayrı çalışmalar mevcuttur. Çalışma kapsamında performansı arttırdığı düşünülen bu iki yönetsel araç araştırma modeline dahil edilmiştir. Analiz sonucunda hem yönetim muhasebesi sisteminin hem de stratejik planlamanın firma performansını pozitif yönde etkilediği tespit edilmiştir. Çalışma bulgumuz, YMS ve firma performansı (Mia, 1993; Mia ve Winata, 2014; Nguyen, 2018) ve stratejik planlama ve firma performansı (Glaister vd., 2008) arasındaki pozitif ilişkiyi bildiren önceki çalışmaları desteklemektedir. Ayrıca yönetim muhasebesi sisteminin firma performansı üzerinde doğrudan etkisinin yanı sıra YMS'nin stratejik planlama aracilığıla firma performansı üzerindeki dolaylı etkisi de anlamlı bulunmuştur. Bu sonuç, stratejik planlamanın YMS ve firma performansı arasındaki kısmi aracı rolünü göstermektedir. Diğer bir ifadeyle, YMS'nin firma performansı üzerindeki etkisinin bir kısmı stratejik planlamadaki rolü aracılığıyla açıklanabilmekte, ancak kalan etki için YMS ve firma performansı arasındaki ilişkiyi açıklayabilecek başka değişkenlerle yürütülecek daha fazla ampirik çalışmaya ihtiyaç duyulmaktadır.

Özetle çalışmamız, yönetim muhasebesi sistemi ve stratejik planlama ilişkisi, YMS'nin firma performansına doğrudan etkisi ve YMS'nin stratejik planlama aracılı̆̆ıyla firma performansına kısmi dolaylı etkisi hakkında literatüre katkı sağlamaktadır.

Çalışmada, Türkiye'nin en büyük kuruluşlarından anket yoluyla elde edilen veri analiz edilmiştir. Gelecek çalışmalarda, daha büyük örneklemlerle ve küçük ve orta ölçekli işletmelerden elde edilecek veri ile araştırma modeli test edilebilir. Çalışmada firma karakteristikleri (firma yaşı, büyüklüğü, sektör vb.) dahil edilmemiştir. Araştırma modeli firma karakteristikleri eklenerek genişletilebilir. Çevresel belirsizlik, rekabet stratejisi ve örgüt kültürü gibi durumsal faktörlerin etkisini inceleyecek çalışmalar yapılabilir. Ayrıca, çalışmamızda stratejik planlamanın YMS'nin firma performansı üzerindeki etkisini kısmen açıkladığı görülmüş olup, araştırma modeli bu ilişkiyi açılayabilecek başka değişkenler eklenerek genişletilebilir.

\section{Hakem Değerlendirmesi / Peer-review:}

Diş bağımsız

Externally peer-reviewed

\section{Çıkar Çatışması / Conflict of interests:}

Yazar(lar) çıkar çatışması bildirmemiştir.

The author(s) has (have) no conflict of interest to declare.

\section{Finansal Destek/ Grant Support:}

Yazar bu çalışma için finansal destek almadığını beyan etmiştir.

The author declared that this study has received no financial support. 


\section{Etik Kurul Onayı / Ethics Committee Approval:}

Bu çalışma için etik kurul onayı, Gebze Teknik Üniversitesi, İnsan Araştırmaları Etik Kurulu 18/02/2021 tarihli 2021/07-02 sayılı karar ile alınmıştır.

Ethics committee approval was received for this study from Gebze Technical University, Human Research Ethics Committee on 18/02/2021 and 2021/07-02 document number.

\section{Yazar Katkıları / Author Contributions:}

Fikir/Kavram/Tasarım - Idea/Concept/Design: G.Ö., C.D., Veri Toplama ve/veya İşleme - Data Collection and/or Processing: C.D., G.Ö., Analiz ve/veya Yorum - Analysis and/or Interpretation: C.D., G.Ö., Kaynak Taraması - Literature Review: C.D., G.Ö., Makalenin Yazımı - Writing the Article: C.D., G.Ö., Eleştirel İnceleme - Critical Review: G.Ö.,C.D., Onay - Approval: G.Ö.,C.D.

\section{Kaynakça / References}

Abernethy, M. A. ve Guthrie, C. H. (1994). An empirical assessment of the "fit" between strategy and management information system design. Accounting and Finance, 34(2), 49-66.

Agbejule, A. (2005). The relationship between management accounting systems and perceived environmental uncertainty on managerial performance: A research note. Accounting and Business Research, 35(4), 295-305.

Agbejule, A. ve Burrowes, A. (2007). Perceived environmental uncertainty, supply chain purchasing strategy, and use of MAS information: An empirical study of Finnish firms. Managerial Auditing Journal, 22(9), 913-927.

Arend, R.J., Zhao, Y.L., Song, M. ve Im, S. (2017). Strategic planning as a complex and enabling managerial tool. Strategic Management Journal, 38, 1741-1752.

Armstrong, J. S. (1982). The value of formal planning for strategic decisions: Review of empirical research. Strategic Management Journal, 3(3), 197-211.

Barney, J. (1991). Firm Resources and Sustained Competitive Advantage. Journal of Management, 17(1), 99-120.

Benitez, J., Henseler, J., Castillo, A. ve Schuberth, F. (2020). How to perform and report an impactful analysis using partial least squares: Guidelines for confirmatory and explanatory IS research. Information and Management, 57(2), 103168.

Bouwens, J. ve Abernethy, M. A. (2000). The consequences of customization on management accounting system design. Accounting, Organizations and Society, 25(3), 221-241.

Boyd, B. K. ve Reuning-Elliott, E. (1998). A Measurement Model of Strategic Planning. Strategic Management Journal, 19(2), 181-192.

Calantone, R.J., Cavusgil, S.T. ve Zhao, Y. (2002). Learning orientation, firm innovation, and firm performance. Industrial Marketing Management, 31 (6), 515-524.

Cheng, M. (2012). The joint effect of budgetary participation and broadscope management accounting systems on management performance. Asian Review of Accounting, 20(3), 184-197.

Chenhall, R. H. (2003). Management control systems design within its organizational context: Findings from contingency-based research and directions for the future. Accounting, Organizations and Society, 28(2), 127-168.

Chenhall, R. H. ve Morris, D. (1986). The Impact of Structure, Environment, and Interdependence on the Perceived Usefulness of Management Accounting Systems. The Accounting Review, 61(1), 1635. 
Chia, Y. M. (1995). Decentralization, Management Accounting System (Mas) Information Characteristics and Their Interaction Effects on Managerial Performance: A Singapore Study. Journal of Business Finance \& Accounting, 22(6), 811-830.

Chiou, B. (2011). Which types of management accounting system information can be used to respond adequately to environmental uncertainty? The effects of user participation and tolerance of ambiguity. African Journal of Business Management, 5(34), 13293-13301.

Chong, V. K. (1996). Management accounting systems, task uncertainty and managerial performance: A research note. Accounting, Organizations and Society, 21(5), 415-421.

Chong, V. K. ve Chong, K. M. (1997). Strategic choices, environmental uncertainty and SBU performance: A note on the intervening role of management accounting systems. Accounting and Business Research, 27(4), 268-276.

Chong, V. K. ve Eggleton, I. R. C. (2003). The Decision-Facilitating Role of Management Accounting Systems on Managerial Performance: The Influence of Locus of Control and Task Uncertainty. Advances in Accounting, 20(03), 165-197.

Cohen, J. (1988). Statistical power analysis for the behavioral sciences. Mahwah, NJ: Lawrence Erlbaum.

Dibrell, C., Craig, J. B. ve Neubaum, D. O. (2014). Linking the formal strategic planning process, planning flexibility, and innovativeness to firm performance. Journal of Business Research, 67(9), 2000-2007.

Etemadi, H., Dilami, Z. D., Bazaz, M. S. ve Parameswaran, R. (2009). Culture, management accounting and managerial performance: Focus Iran. Advances in Accounting, 25(2), 216-225.

Falshaw, J. R., Glaister, K. W. ve Tatoglu, E. (2006). Evidence on formal strategic planning and company performance. Management Decision, 44(1), 9-30.

Fisher, C. (1996). The impact of perceived environmental uncertainty and individual differences on management information requirements: A research note. Accounting, Organizations and Society, 21(4), 361-369.

Fornell, C. ve Larcker, D. F. (1981). Evaluating Structural Equation Models with Unobservable Variables and Measurement Error. Journal of Marketing Research, 18(1), 39.

Frezatti, F., Aguiar, A. B., Guerreiro, R. ve Gouvea, M. A. (2011). Does management accounting play role in planning process? Journal of Business Research, 64(3), 242-249.

Ghasemi, R., Habibi, H. R., Ghasemlo, M. ve Karami, M. (2019). The effectiveness of management accounting systems: Evidence from financial organizations in Iran. Journal of Accounting in Emerging Economies, 9(2), 182-207.

Ghasemi, R., Mohamad, N. A., Karami, M., Bajuri, N. H. ve Asgharizade, E. (2016). The mediating effect of management accounting system on the relationship between competition and managerial performance. International Journal of Accounting and Information Management, 24(3), 272-295.

Ghasemi, R., Mohamad, N. A., Karami, M., Hafiz Bajuri, N. ve Asgharizade, E. (2015). The Relationship among Strategy, Competition and Management Accounting Systems on Organizational Performance. European Online Journal of Natural and Social Sciences, 4(3), 565-581.

Glaister, K. W., Dincer, O., Tatoglu, E., Demirbag, M. ve Zaim, S. (2008). A causal analysis of formal strategic planning and firm performance: Evidence from an emerging country. Management Decision, 46(3), 365-391.

Govindarajan V. (1984). Appropriateness of accounting data in performance evaluation: an empirical examination of environmental uncertainty as an intervening variable. Accounting, Organizations and Society, 9, 125-135

Grant, R. M. (2003). Strategic planning in a turbulent environment: Evidence from the oil majors. Strategic Management Journal, 24(6), 491-517.

Greenley, G. E. (1994). Strategic planning and company performance: An appraisal of the empirical evidence. Scandinavian Journal of Management, 10(4), 383-396.

Gul, F. A. ve Chia, Y. M. (1994). The effects of management accounting systems, perceived environmental uncertainty and decentralization on managerial performance: A test of three-way interaction. Accounting, Organizations and Society, 19(4-5), 413-426. 
Hair, J.F., Hult, G.T.M., Ringle, C.M. ve Sarstedt, M. (2017) A Primer on Partial Least Squares Structural Equation Modeling (PLS-SEM). 2nd Ed., Sage, Thousand Oaks.

Hair, J. F., Risher, J. J., Sarstedt, M. ve Ringle, C. M. (2019). When to use and how to report the results of PLS-SEM. European Business Review, 31(1), 2-24.

Hammad, S. A., Jusoh, R. ve Ghozali, I. (2013). Decentralization, perceived environmental uncertainty, managerial performance and management accounting system information in Egyptian hospitals. International Journal of Accounting and Information Management, 21(4), 314-330.

Henseler, J., Ringle, C. M. ve Sarstedt, M. (2015). A new criterion for assessing discriminant validity in variance-based structural equation modeling. Journal of the Academy of Marketing Science, 43(1), $115-135$.

Hopkins, W. E. ve Hopkins, S. A. (1997). Strategic planning-financial performance relationships in banks: A causal examination. Strategic Management Journal, 18(8), 635-652.

Hutahayan, B. (2020). The mediating role of human capital and management accounting information system in the relationship between innovation strategy and internal process performance and the impact on corporate financial performance. Benchmarking, 27(4), 1289-1318.

Ismail, K., Isa, C. R. ve Mia, L. (2018). Evidence on the usefulness of management accounting systems in integrated manufacturing environment. Pacific Accounting Review, 30(1), 2-19.

Lal, M. ve Hassel, L. (1998). The joint impact of environmental uncertainty and tolerance of ambixguity on top managers' perceptions of the usefulness of non-conventional management accounting information. Scandinavian Journal of Management, 14(3), 259-271.

Lawrence, P. R. ve Lorsch, J. W. (1967). Differentiation and Integration in Complex Organizations. Administrative Science Quarterly, 12(1), 1.

Linn, G., Casey, K. M., Johnson, G. H. ve Ellis, T. S. (2001). Do broad scope managerial accounting systems moderate the effects of budget emphasis, budget participation and perceived environmental uncertainty on the propensity to create budgetary slack? Journal of Computer Information Systems, 42(1), 90-96.

McCarthy, D. J. ve Minichiello, R. J. (1996). Business policy and strategy, concepts and readings. 4th ed. Homewood, IL: Richard D. Irwin.

Meissner, P. (2014). A process-based perspective on strategic planning: The role of alternative generation and information integration. Business Research, 7(1), 105-124.

Mia, L. (1993). The Role Of Mas Information In Organisations: An Empirical Study. British Accounting Review, 25(3), 269-285.

Mia, L. (2000). Just-in-time manufacturing, management accounting systems and profitability. Accounting and Business Research, 30(2), 137-151.

Mia, L. ve Chenhall, R. H. (1994). The usefulness of management accounting systems, functional differentiation and managerial effectiveness. Accounting, Organizations and Society, 19(1), 1-13.

Mia, L. ve Clarke, B. (1999). Market competition, management accounting systems and business unit performance. Management Accounting Research, 10(2), 137-158.

Mia, L. ve Winata, L. (2008). Manufacturing strategy, broad scope MAS information and information and communication technology. British Accounting Review, 40(2), 182-192.

Mia, L. ve Winata, L. (2014). Manufacturing strategy and organisational performance: The role of competition and MAS information. Journal of Accounting and Organizational Change, 10(1), 83-115.

Miller, C. C. ve Cardinal, L. B. (1994). Strategic Planning and Firm Performance: A Synthesis of More Than Two Decades of Research. Academy of Management Journal, 37(6), 1649-1665.

Naranjo-Gil, D. ve Hartmann, F. (2007). Management accounting systems, top management team heterogeneity and strategic change. Accounting, Organizations and Society, 32(7-8), 735-756.

Nguyen, N. P. (2018). Performance implication of market orientation and use of management accounting systems. Journal of Asian Business and Economic Studies, 25(1), 33-49.

Nguyen, T. T., Mia, L., Winata, L. ve Chong, V. K. (2017). Effect of transformational-leadership style and management control system on managerial performance. Journal of Business Research, 70, 202-213. 
Novas, J. C., Alves, M. do C. G. ve Sousa, A. (2017). The role of management accounting systems in the development of intellectual capital. Journal of Intellectual Capital, 18(2), 286-315.

Otley, D. T. (1980). The contingency theory of management accounting: Achievement and prognosis. Accounting, Organizations and Society, 5(4), 413-428.

Patiar, A. ve Mia, L. (2008). The Interactive Effect of Market Competition and Use of MAS Information on Performance: Evidence From the Upscale Hotels. Journal of Hospitality and Tourism Research, 32(2), 209-234.

Pearce, J. A., Freeman, E. B. ve Robinson, R. B. (1987). The Tenuous Link between Formal Strategic Planning and Financial Performance. The Academy of Management Review, 12(4), 658.

Pedroso, E., Gomes, C. F. ve Yasin, M. M. (2020). Management accounting systems: An organizational competitive performance perspective. Benchmarking, 27(6), 1843-1874.

Rasid, S. Z. A., Isa, C. R. ve Ismail, W. K. W. (2014). Management accounting systems, enterprise risk management and organizational performance in financial institutions. Asian Review of Accounting, 22(2), 128-144.

Ringle, C. M., Wende, S. ve Becker, J.-M. (2015). SmartPLS 3. Boenningstedt: SmartPLS GmbH, http://www.smartpls.com.

Sarstedt, M., Hair, J. F., Cheah, J. H., Becker, J. M. ve Ringle, C. M. (2019). How to specify, estimate, and validate higher-order constructs in PLS-SEM. Australasian Marketing Journal, 27(3), 197-211.

Sax, J. ve Andersen, T. J. (2019). Making Risk Management Strategic: Integrating Enterprise Risk Management with Strategic Planning. European Management Review, 16(3), 719-740.

Sharma, R., Jones, S. ve Ratnatunga, J. (2006). The relationships among broad scope MAS, managerial control, performance, and job relevant information: A concomitant analysis. Review of Accounting and Finance, 5(3), 228-250.

Shea-Van Fossen, R. J., Rothstein, H. R. ve Korn, H. J. (2006). Thirty-five years of strategic planning and firm performance research: A meta-analysis. Academy of Management 2006 Annual Meeting: Knowledge, Action and the Public Concern, AOM 2006, 1-7.

Shmueli, G., Ray, S., Velasquez Estrada, J. M. ve Chatla, S. B. (2016). The elephant in the room: Predictive performance of PLS models. Journal of Business Research, 69(10), 4552-4564.

Shmueli, G., Sarstedt, M., Hair, J. F., Cheah, J. H., Ting, H., Vaithilingam, S. ve Ringle, C. M. (2019). Predictive model assessment in PLS-SEM: guidelines for using PLSpredict. European Journal of Marketing, 53(11), 2322-2347.

Soobaroyen, T. ve Poorundersing, B. (2008). The effectiveness of management accounting systems: Evidence from functional managers in a developing country. Managerial Auditing Journal, 23(2), 187-219.

Tsui, J. S. L. (2001). The impact of culture on the relationship between budgetary participation, management accounting systems, and managerial performance: An analysis of Chinese and Western managers. International Journal of Accounting, 36(2), 125-146.

Wolf, C. ve Floyd, S. W. (2017). Strategic Planning Research: Toward a Theory-Driven Agenda. Journal of Management, 43(6), 1754-1788. 